\title{
Cationic Cycloheptatrienyl Cyclopentadienyl Manganese Sandwich Complexes: Tromancenium Explored with High-Power LED Photosynthesis
}

\author{
Reinhard Basse, $^{\dagger}$ Stefan Vanicek, ${ }^{\dagger}$ Thomas Höfer, Holger Kopacka, Klaus Wurst, Thomas Müller, \\ Heidi A. Schwartz, Selina Olthof, Larissa A. Casper, Moritz Nau, Rainer F. Winter,* Maren Podewitz,* \\ and Benno Bildstein*
}

Cite This: Organometallics 2021, 40, 2736-2749

Read Online

ABSTRACT: In this contribution, we revisit the neglected and forgotten cationic, air-stable, 18valence electron, heteroleptic sandwich complex (cycloheptatrienyl)(cyclopentadienyl)manganese, which was reported independently by Fischer and by Pauson about 50 years ago. Using advanced high-power LED photochemical synthesis, an expedient rapid access to the parent complex and to functionalized derivatives with alkyl, carboxymethyl, bromo, and amino substituents was developed. A thorough study of these "tromancenium" salts by a range of spectroscopic techniques $\left({ }^{1} \mathrm{H} /{ }^{13} \mathrm{C} /{ }^{55} \mathrm{Mn}\right.$ NMR, IR, UV-vis, HRMS, XRD, XPS, EPR), cyclic voltammetry (CV), and quantum chemical calculations (DFT) shows that these manganese sandwich complexes are unique metallocenes with quite different chemical and physical properties in comparison to those of isoelectronic cobaltocenium salts or (cycloheptatrienyl)(cyclopentadienyl) sandwich complexes of the early

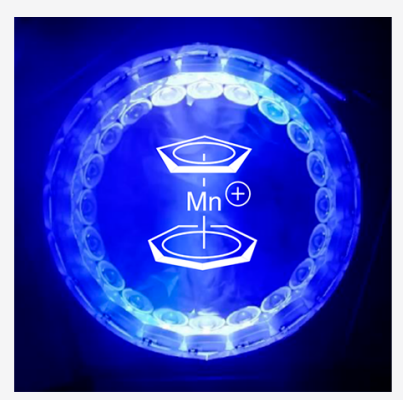
transition metals. Electrochemically, all tromancenium ions undergo a chemically partially reversible oxidation and a chemically irreversible reduction at half-wave or peak potentials that respond to the substituents at the Cp deck. As exemplarily shown for the parent tromancenium ion, the product generated during the irreversible reduction process reverts at least partially to the starting material upon reoxidation. Quantum-chemical calculations of the parent tromancenium salt indicate that metal-ligand bonding is distinctly weaker for the cycloheptatrienyl ligand in comparison to that of the cyclopentadienyl ligand. Both the HOMO and the LUMO are metal and cycloheptatrienyl-ligand centered, indicating that chemical reactions will occur either metal-based or at the seven-membered ring, but not on the cyclopentadienyl ligand.

\section{INTRODUCTION}

Among the huge number of metal sandwich complexes known in organometallic chemistry, the class of heteroleptic (cycloheptatrienyl)(cyclopentadienyl) metal complexes $[(\mathrm{Cht}) \mathrm{M}(\mathrm{Cp})]^{ \pm n}$ constitutes an interesting family of compounds, mostly restricted to early transition metals, as shown by the work of Green, ${ }^{1}$ Elschenbroich, ${ }^{2}$ Tamm, ${ }^{3}$ and Braunschweig. ${ }^{4}$ Table 1 summarizes the known representatives commonly called "tro-met-cenes" where "tro" stands for tropylium $\left(\mathrm{C}_{7} \mathrm{H}_{7}\right)^{+}$, "met" for the metal center, and "cene" for a cyclopentadienide-containing sandwich complex. For example, the corresponding titanium, vanadium, or chromium species are called troticene, trovacene, and trochrocene, respectively. Whereas the chemistry of the group 4, 5, and 6 trometcenes has been and still is frequently studied, ${ }^{3,4}$ the representatives of manganese and ruthenium seem to be totally neglected sandwich complexes. This is rather surprising because these complexes are air-stable, redox-responsive 18valence electron species, isoelectronic to ferrocene, with potentially similar useful properties and applications. We have previously contributed to this area with a publication on tropolone-based trorucenium metalloligands ${ }^{5}$ and would like
Table 1. Overview of Cycloheptatrienyl Cyclopentadienyl Transition Metal Sandwich Complexes ${ }^{a}$

$\begin{array}{ccccc}\text { group } 4 & \text { group } 5 & \text { group 6 } & \text { group 7 } & \text { group } 8 \\ {[(\mathrm{Cht})} & {[(\mathrm{Cht})} & {[(\mathrm{Cht})} & & \\ \mathbf{T i}(\mathrm{Cp})]^{-} & \mathbf{V}(\mathrm{Cp})]^{-} & \mathbf{C r}(\mathrm{Cp})]^{-} & & \\ {[(\mathrm{Cht})} & {[(\mathrm{Cht})} & {[(\mathrm{Cht})} & {[(\mathrm{Cht})} & \\ \mathbf{T i}(\mathrm{Cp})] & \mathbf{V}(\mathrm{Cp})] & \mathbf{C r}(\mathrm{Cp})] & \mathbf{M n}(\mathrm{Cp})]^{+} & \\ & {[(\mathrm{Cht})} & {[(\mathrm{Cht})} & & \\ & \mathbf{V}(\mathrm{Cp})]^{+} & \mathbf{C r}(\mathrm{Cp})]^{+} & & {[(\mathrm{Cht})} \\ {[(\mathrm{Cht})} & {[(\mathrm{Cht})} & {[(\mathrm{Cht})} & \mathbf{R u}(\mathrm{Cp})]^{2+} \\ \mathbf{Z r}(\mathrm{Cp})] & \mathbf{N b}(\mathrm{Cp})] & \mathbf{M o}(\mathrm{Cp})] & \\ {[(\mathrm{Cht})} & {[(\mathrm{Cht})} & {[(\mathrm{Cht})} & \\ \mathbf{H f}(\mathrm{Cp})] & \mathbf{T a}(\mathrm{Cp})] & \mathbf{W}(\mathrm{Cp})] & & \\ { }^{a} \mathrm{Cht}=\eta^{7} \text {-cycloheptatrienyl, Cp }=\eta^{5} \text {-cyclopentadienyl. } & \end{array}$

Received: June 23, 2021

Published: July 27, 2021 
Scheme 1. Fischer's (Top) and Pauson's (Bottom) Synthesis of the First Tromancenium Derivatives




6: $R, R^{\prime}=H$ 7: $\mathrm{R}=\mathrm{H}, \mathrm{R}^{\prime}=\mathrm{CH}_{3}$ 8: $\mathrm{R}=\mathrm{CH}_{3}, \mathrm{R}^{\prime}=\mathrm{H}$
3: $\mathrm{R}=\mathrm{C}_{6} \mathrm{H}_{5},<1 \%$ yield



9: $R, R^{\prime}=H^{(80 \%}$ yield $)$

10: $\mathrm{R}=\mathrm{H}, \mathrm{R}^{\prime}=\mathrm{CH}_{3}(40 \%$ yield $)$

11: $R=\mathrm{CH}_{3}, \mathrm{R}^{\prime}=\mathrm{H}(77 \%$ yield $)$

Scheme 2. High-Power LED Photosynthesis of Tromancenium Salts

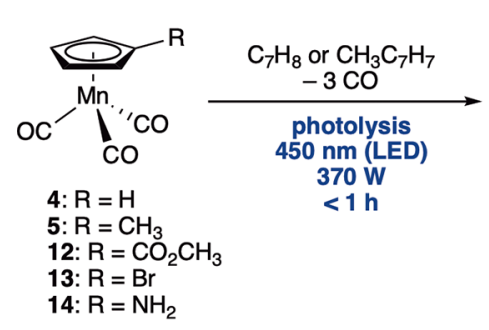

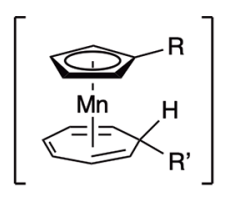

6: $R, R^{\prime}=H$

7: $\mathrm{R}=\mathrm{H}, \mathrm{R}^{\prime}=\mathrm{CH}_{3}$

8: $\mathrm{R}=\mathrm{CH}_{3}, \mathrm{R}^{\prime}=\mathrm{H}$

15: $\mathrm{R}=\mathrm{CO}_{2} \mathrm{CH}_{3}, \mathrm{R}^{\prime}=\mathrm{H}$

16: $\mathrm{R}=\mathrm{Br}, \mathrm{R}^{\prime}=\mathrm{H}$

17: $\mathrm{R}=\mathrm{NH}_{2}, \mathrm{R}^{\prime}=\mathrm{H}$

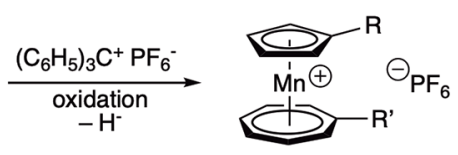

9: $R, R^{\prime}=H(74 \%$ yield $)$

10: $\mathrm{R}=\mathrm{H}, \mathrm{R}^{\prime}=\mathrm{CH}_{3}(25 \%$ yield $)$

11: $\mathrm{R}=\mathrm{CH}_{3}, \mathrm{R}^{\prime}=\mathrm{H}(97 \%$ yield $)$

18: $\mathrm{R}=\mathrm{CO}_{2} \mathrm{CH}_{3}, \mathrm{R}^{\prime}=\mathrm{H}(19 \%$ yield $)$

19: $R=B r, R^{\prime}=H^{\prime}(24 \%$ yield $)$

20: $\mathrm{R}=\mathrm{NH}_{2}, \mathrm{R}^{\prime}=\mathrm{H}(10 \%$ yield $)$ to report here on new advances in tromancenium chemistry. The first and only representatives of simple tromancenium complexes were reported half a century ago independently by Fischer ${ }^{6}$ and by Pauson, ${ }^{7}$ but surprisingly, no further publications on this subject have appeared since then. Tromancenium salts are interesting monocationic sandwich compounds, isoelectronic to cobaltocenium salts, ${ }^{8}$ with prospective similarly advantageous properties, including high polarity, good solubility in polar solvents, redox-activity, and nontoxic character. All of these are desirable features in green chemistry, medicinal chemistry, and electrocatalysis. In addition, this research is a contribution to current efforts in homogeneous catalysis focusing on Earth-abundant, first-row transition metals like manganese, iron, and cobalt (so-called "base metals") as alternatives to rare and expensive $4 \mathrm{~d}$ and $5 \mathrm{~d}$ elements. ${ }^{9}$

\section{RESULTS AND DISCUSSION}

State of Knowledge on the Chemistry of Tromancenium Salts. Tromancenium is a "forgotten" stable $\pi$-sandwich species, most likely because it is quite difficult to prepare. In 1966, Fischer and Breitschaft ${ }^{6}$ obtained by accident and in poor yield 1-methyltromancenium hexafluoridophosphate (2) and 1-phenyltromancenium hexafluoridophosphate (3), respectively, when they attempted Friedel-Crafts acylation of (benzene)(cyclopentadienyl)manganese(I) (1) (Scheme 1). Chemically, this is an interesting, unusual ring-expansion of benzene to a seven-membered $\pi$-conjugated cyclic ligand by formal electrophilic attack of $\left[\mathrm{CH}_{3}-\mathrm{C}^{+}\right]$or $\left[\mathrm{C}_{6} \mathrm{H}_{5}-\mathrm{C}^{+}\right]$, which indicates a high thermodynamic stability of the tromancenium moiety. From a synthetic chemist's viewpoint, this reaction is of no further value, also because the starting complex $\mathbf{1}$ is accessible in only less than $3 \%$ yield. ${ }^{6} \mathrm{~A}$ few years later, in 1973, Pauson and Segal ${ }^{7}$ reported a clean and straightforward synthesis of the parent tromancenium hexafluoridophosphate
(9, 80\% isolated yield), of 1-methyltromancenium hexafluoridophosphate (10,40\% yield) and of 8-methyltromancenium hexafluoridophosphate $(11,77 \%$ yield $)$ by photochemical displacement of all three CO ligands of tricarbonyl(cyclopentadienyl)manganese (4) or tricarbonyl(methylcyclopentadienyl)manganese (5) with cycloheptatriene or methylcycloheptatriene to the corresponding cyclopentadienyl-triene- $\mathrm{Mn}(\mathrm{I})$ complexes $\mathbf{6 - 8}$, followed by oxidation/ hydride abstraction with tritylium hexafluoridophosphate (Scheme 1). This photochemical protocol looks at first sight very promising. However, in reality, it is rather difficult to perform because intermediates $\mathbf{6}-\mathbf{8}$ are highly air-sensitive and-in practice even more relevant-acceptable yields are only obtained using a falling film photoreactor, ${ }^{7 \mathrm{c}}$ which is an expensive specialized equipment not available in most laboratories. The tromancenium salts 2, 9, 10, and 11 have been described as air-stable, pink, polar, diamagnetic compounds and were spectroscopically characterized by IR and ${ }^{1} \mathrm{H}$ NMR spectroscopy only. ${ }^{6,7}$ In particular, no singlecrystal structure analyses or electrochemical properties have been reported.

High-Power LED Photochemical Synthesis. In comparison to common photochemical synthesis using standard medium-pressure mercury lamps, modern light-emitting diodes (LEDs) provide improved conditions using high-intensity monochromatic light that excites one specific transition and hence has the propensity to selectively activate a desired chemical process. We used here a custom-made photochemical reactor called "Solar Light Lab Luminaire" (see the Experimental Section) based on high-power LEDs developed in collaboration with the Austrian company Bartenbach. ${ }^{10}$ This apparatus proved extremely useful for our purposes. It allows very convenient, rapid, selective, high-power photochemical synthesis (270-370 W per channel) for five wavelengths from the UV to the visible part of the spectrum (UV-1:360 nm, UV- 
2:405 nm, blue: $450 \mathrm{~nm}$, green: $535 \mathrm{~nm}$, cold white $(5000 \mathrm{~K}))$. By using blue light and an irradiation period of only $1 \mathrm{~h}$ or less, we are able to obtain the intermediate 6,7 , or 8 in a straightforward manner (Scheme 2). Further reaction with tritylium hexafluoridophosphate afforded the desired tromancenium salts 9, 10, and 11 in $97-25 \%$ isolated yield on a $1 \mathrm{~g}$ scale, corresponding to an overall quantum yield of $2.9 \%$ (for 9), 5.3\% (for 10 ), and 3.2\% (for 11 ), respectively. In the case of 1-methyl-substituted tromancenium 10, the chemical yield dropped to $10 \%$ due to competing cycloaddition reactions of the methylcycloheptatriene ligand. This is a general problem, as attempted reactions with other substituted cycloheptatrienes like cyano or ethynyl cycloheptatriene failed to provide the desired cycloheptatriene complexes. Hence, mostly 8-substituted tromancenium compounds are accessible by this procedure. Nevertheless, this LED-based approach is clearly much more convenient than Pauson's original procedure using a traditional medium-pressure mercury lamp in a falling film photoreactor with irradiation times of $8 \mathrm{~h}^{7}$

Having methylated tromancenium salts 10 and 11 in hand, we anticipated that aromatic side-chain oxidation with aqueous $\mathrm{KMnO}_{4}$ would cleanly afford the corresponding carboxylic acids, in analogy to such established reactivity in cobaltocenium chemistry. ${ }^{8 a}$ Surprisingly, only unreacted methylated starting materials $\mathbf{1 0}$ and $\mathbf{1 1}$ were recovered after the reactions, although discoloration of the purple $\mathrm{KMnO}_{4}$ solution and concomitant formation of $\mathrm{MnO}_{2}$ precipitate were observed. Interestingly, the same result was also obtained with nonmethylated tromancenium salt 9, suggesting that tromancenium-catalyzed decomposition of permanganate took place instead of the desired aromatic side-chain oxidation. Attempts with various other oxidizing agents gave the same negative result.

An alternative synthetic access to tromancenium carboxylic acids was therefore required. Starting from cymantrenecarboxylic acid, ${ }^{11}$ photochemical substitution of the carbonyl ligands by cycloheptatriene followed by oxidation/hydride removal with tritylium was attempted, but without any success, suggesting that the carboxylic acid functionality is incompatible with our photochemical reaction conditions. To circumvent this problem, the methyl ester of cymantrenecarboxylic acid $(\mathbf{1 2})^{12}$ as an O-protected synthon was used, and indeed, the corresponding 8-methoxycarbonyltromancenium hexafluoridophosphate (18) was obtained in 19\% isolated yield (Scheme 2). Deprotection by alkaline hydrolysis to the desired tromancenium-8-carboxylic acid was attempted, but unfortunately, under these highly basic conditions only decomposition was observed. Hence, at the current state, tromanceniumcarboxylic acid remains an elusive target compound that needs to be made by other methods.

Next, we were interested if cymantrene derivatives containing other valuable functional groups are also suitable for the photochemical conversion to tromancenium salts. Satisfyingly, with bromocymantrene $(13)^{13}$ the corresponding 8-bromotromancenium complex 19 was obtained in $24 \%$ chemical and in $2.7 \%$ quantum yield. In practice, the photochemical reaction of halogenated cymantrene derivatives needed careful optimization of the irradiation times: for bromocymantrene a very short duration of $2.30 \mathrm{~min}$ proved optimal whereas attempted analogous reaction with iodocymantrene ${ }^{14}$ resulted in complete decomposition, even after short irradiation times. Not unexpectedly, halogenated precursors are quite labile under these harsh photochemical conditions. A further very useful functional group is the amino group. Interestingly, even with this reactive substituent, the desired 8-aminotromancenium complex 20 was obtained on a $0.50 \mathrm{mmol}$ scale by irradiation of aminocymantrene $(\mathbf{1 4})^{15}$ for $3.40 \mathrm{~min}$ followed by oxidation with tritylium in $9.5 \%$ chemical and in $8.4 \%$ quantum yield.

A general and useful derivatization strategy of cationic sandwich metal complexes (for example cobaltocenium salts) is nucleophilic exoaddition of various nucleophiles to provide neutral, functionalized endohydride derivatives that may subsequently be oxidized with tritylium to valuable substituted sandwich metal cations. ${ }^{8 \mathrm{a}, 16}$ Attempted reactions of tromancenium complex 9 with a range of carbon, nitrogen, or oxygen nucleophiles resulted, unfortunately, only in complete decomposition of the manganese sandwich complex, indicating that tromancenium salts are surprisingly labile in comparison to other cationic metallocenes, due to rather weak bonding of the cycloheptatrienyl ligand (vide infra).

To summarize this synthetic section, high-power LED photochemistry of metal carbonyl complexes is convenient, fast, and superior to standard methodology. For tromancenium compounds, LED photochemistry with blue light proved very useful and provided rapid access to several target complexes, including highly valuable functionalized derivatives. Preferred starting materials are functionalized cymantrene complexes ${ }^{17}$ that are known in a large structural variety, thereby opening up interesting options for future developments in this class of compounds. On the other hand, tromancenium salts are quite susceptible to nucleophile-triggered degradation, thereby prohibiting derivatization methods involving nucleophilic attack on the cycloheptatrienylium ligand, which are well established for other cationic sandwich complexes. ${ }^{16}$

Physical, Structural, And Spectroscopic Properties. Tromancenium salts 9-11 and 18-20 are air-stable, red crystalline solids with high melting points in the range of 206$256{ }^{\circ} \mathrm{C}$ (see the Experimental Section). They are soluble in polar solvents like acetonitrile, acetone, dimethylformamide, and dimethyl sulfoxide and also slightly soluble in water. Dilute solutions are pink, by coincidence very similar to the shady pink color of aqueous solutions of simple inorganic $\mathrm{Mn}^{2+}$ salts. UV-vis spectra reveal corresponding absorptions at 277-290 and 500-569 nm, respectively. Positive-mode ESI highresolution mass spectra show signals of the most abundant monoisotopic peaks of the cations in excellent agreement with calculated values, thereby proving further the identity of these salts. IR spectra are rather unremarkable with dominating strong absorptions of the hexafluoridophosphate anions observed at $808-826$ and $554-556 \mathrm{~cm}^{-1}$.

${ }^{1} \mathrm{H}$ NMR spectra of $\mathbf{9 - 1 1}$ and 18-20 are overall rather simple (see the Experimental Section). The unsubstituted Cp ligands of 9 and 10 give rise to singlets at 4.73 or $4.67 \mathrm{ppm}$, whereas pseudotriplets for 11,18 , and 19 are detected at 4.67-5.20 $\mathrm{ppm}$. In contrast, the protons of the unsubstituted Cht ligands of 9, 11, and 18-20 resonate at 6.63-6.84 ppm and are clearly deshielded in comparison to those of the $\mathrm{Cp}$ ligands, as expected for a formal cationic tropylium ligand. Quite similarly, ${ }^{13} \mathrm{C}$ NMR spectra 9-11, 18, and 19 give $\mathrm{Cp}$ signals in the range of 77.3-86.4 and Cht signals in the range of 96.0-99.4 ppm, respectively. The ${ }^{1} \mathrm{H} /{ }^{13} \mathrm{C}$ NMR data for aminotromancenium $20\left(\delta\left({ }^{1} \mathrm{H}\right.\right.$ of $\left.\mathrm{Cp}\right)=4.32-4.43 \mathrm{ppm}, \delta$ $\left({ }^{1} \mathrm{H}\right.$ of $\left.\mathrm{Cht}\right)=6.63 \mathrm{ppm}, \delta\left({ }^{13} \mathrm{C}\right.$ of $\mathrm{Cp}=65.3,73.3,123.9$ $\mathrm{ppm}), \delta\left({ }^{13} \mathrm{C}\right.$ of $\left.\mathrm{Cht}=97.5 \mathrm{ppm}\right)$ are slightly different from those of the other tromancenium complexes. This is due to the 




Figure 1. Overlay of ${ }^{55} \mathrm{Mn}$ spectra of tromancenium salts in $\mathrm{CD}_{3} \mathrm{CN}$ solution, referenced versus saturated $\mathrm{KMnO}_{4} / \mathrm{D}_{2} \mathrm{O}$ solution: 9, 271; 10, 378; 11, 257; 18, 538; 19, 368; 20, 238 ppm.

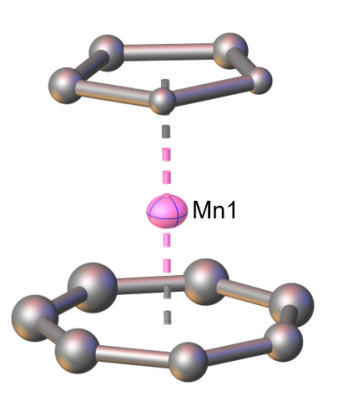

9

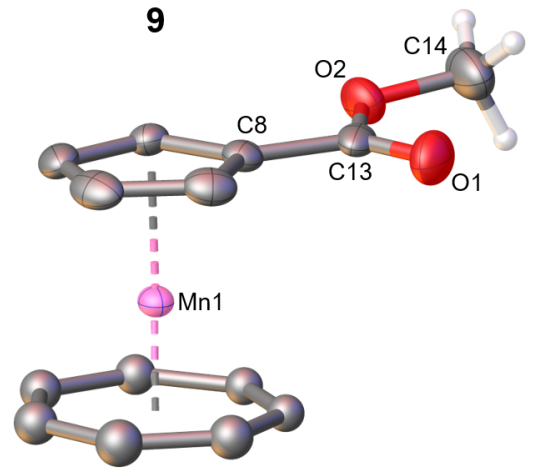

18



10



19

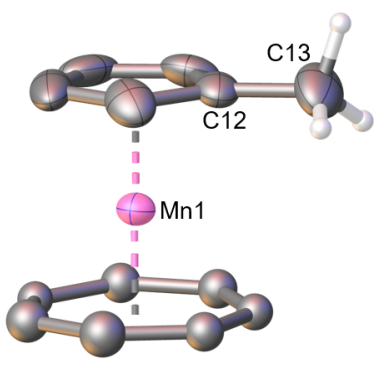

11

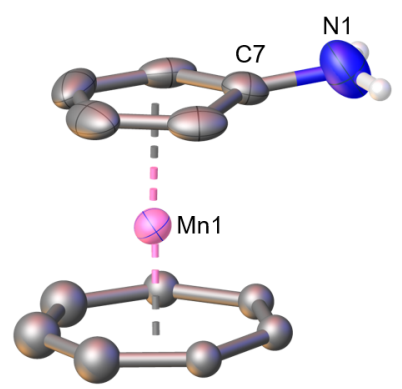

20

Figure 2. Molecular structures of tromancenium salts 9, 10, 11, 18, 19, and 20. Counteranions $\mathrm{PF}_{6}{ }^{-}$and hydrogen atoms of the Cht and $\mathrm{Cp}$ ligands are omitted for clarity reasons. Selected bond lengths $(\AA): 9: \mathrm{Mn}-\mathrm{C}_{\mathrm{Cht}}(\mathrm{avg})=2.13, \mathrm{Mn}-\mathrm{C}_{\mathrm{Cp}}(\mathrm{avg})=2.10 ; 10: \mathrm{Mn}-\mathrm{C}_{\mathrm{Cht}}(\mathrm{avg})=2.14, \mathrm{Mn}-$ $\mathrm{C}_{\mathrm{Cp}}(\mathrm{avg})=2.11, \mathrm{C} 1-\mathrm{C} 5=1.51(5) ; 11: \mathrm{Mn}-\mathrm{C}_{\mathrm{Cht}}(\mathrm{avg})=2.10, \mathrm{Mn}-\mathrm{C}_{\mathrm{Cp}}(\mathrm{avg})=2.12, \mathrm{C} 12-\mathrm{C} 13=1.49(8) ; 18: \mathrm{Mn}-\mathrm{C}_{\mathrm{Cht}}(\mathrm{avg})=2.13, \mathrm{Mn}-$ $\mathrm{C}_{\mathrm{Cp}}(\mathrm{avg})=2.12, \mathrm{C} 8-\mathrm{C} 13=1.49(4), \mathrm{C} 13-\mathrm{O} 1=1.20(4), \mathrm{C} 13-\mathrm{O} 2=1.32(4) ; 19: \mathrm{Mn}-\mathrm{C}_{\mathrm{Cht}}(\mathrm{avg})=2.14, \mathrm{Mn}-\mathrm{C}_{\mathrm{Cp}}(\mathrm{avg})=2.12, \mathrm{C} 12-\mathrm{Br} 1=$ $1.88(3) ; 20: \mathrm{Mn}-\mathrm{C}_{\mathrm{Cht}}(\mathrm{avg})=1.98, \mathrm{Mn}-\mathrm{C}_{\mathrm{Cp}}(\mathrm{avg})=2.10, \mathrm{Mn}-\mathrm{C} 12=2.22(1), \mathrm{C} 7-\mathrm{N} 1=1.35(1)$.

amino donor substituent that imparts some fulvenoid iminium distortion, analogously to aminocobaltocenium salts. ${ }^{8 \mathrm{~b}}$ In addition, ${ }^{1} \mathrm{H} /{ }^{13} \mathrm{C}$ signals for the methyl groups of $\mathbf{1 0}$ and $\mathbf{1 1}$ as well as signals for the carboxymethyl substituent of $\mathbf{1 8}$ and of the amino group of $\mathbf{2 0}$ are observed in the expected spectral regions.

${ }^{55} \mathrm{Mn}$-NMR spectroscopy provides a further uncommon option to gain direct information on the electronic properties of the metal center of tromancenium salts. In general, ${ }^{55} \mathrm{Mn}$ NMR is only rarely conducted despite its high sensitivity (natural abundance: $100 \%$; receptivity relative to ${ }^{1} \mathrm{H}: 0.179$ ) because the high nuclear electric quadrupole moment $(Q=$ $\left.0.40 \times 10^{-28} \mathrm{~m}^{2}, I=5 / 2\right)$ prevents the observation of signals for diamagnetic compounds of low symmetry. Diamagnetic manganese compounds are restricted to oxidation states $-1,0$, +1 , and +7 , which, taken together with the predominance of 
high-spin complexes in oxidation states +2 and +3 , limits the utility of ${ }^{55} \mathrm{Mn}$ NMR spectroscopy in manganese coordination chemistry. However, Wrackmeyer ${ }^{18}$ obtained for a series of (arene)(cyclopentadienyl)Mn(I) complexes easily observable, fairly well resolved ${ }^{55} \mathrm{Mn}$ NMR spectra with peak widths at half-height of only a few $\mathrm{kHz}$, showing that such $\mathrm{Mn}(\mathrm{I})$ sandwich complexes are sufficiently "symmetric" with only small deviations from spherical charge distributions at the $\mathrm{Mn}$ nucleus. Gratifyingly, also tromancenium salts 9-11 and 1820 gave very good ${ }^{55} \mathrm{Mn}$ spectra (Figure 1, Experimental Section) with peak widths of approximately $1.5 \mathrm{kHz}$. Only aminotromancenium 20 displayed a broader signal. This agrees with a lower symmetry of the aminocyclopentadienyl ligand due to its partial iminium fulvene character. The ${ }^{55} \mathrm{Mn}$ chemical shifts of 9-11 and 18-20 spread over a narrow range of $300 \mathrm{ppm}$, from 238 to $538 \mathrm{ppm}$, in line with their similar local ligand sphere at the manganese center. In general, ${ }^{55} \mathrm{Mn}$ NMR is quite sensitive to electronic structure, as can be seen by comparison of the shift data of the tromancenium ions with those of $\left(\eta^{5}-\mathrm{C}_{5} \mathrm{H}_{5}\right) \mathrm{Mn}\left(\eta^{6}-\mathrm{C}_{7} \mathrm{H}_{8}\right)(6), \delta\left({ }^{55} \mathrm{Mn}\right)=1077$ ppm, ${ }^{18}$ and cymantrene $\left(\eta^{5}-\mathrm{C}_{5} \mathrm{H}_{5}\right) \mathrm{Mn}(\mathrm{CO})_{3}(4), \delta\left({ }^{55} \mathrm{Mn}\right)=$ 2060 ppm. ${ }^{19}$ No linear correlation of ${ }^{55} \mathrm{Mn}$ chemical shifts with Hammett substituent parameters was observed though, ${ }^{20}$ as it is rather common in transition metal NMR spectroscopy.

The tromancenium salts crystallize readily, and single-crystal $\mathrm{X}$-ray analyses are available for all six compounds (Figure 2, Supporting Information). Overall, the tromancenium cations display the typical sandwich metal structure of a central metal coordinated to parallel displaced carbocyclic ligands. The average manganese-carbon bond lengths are very similar for the Cp ligands $(2.10-2.12 \AA)$ and for the Cht ligands (2.10$2.14 \AA)$. This drags the larger Cht ligands closer to the manganese centers with corresponding shorter $\mathrm{Mn}-\mathrm{Cht}_{\text {centroid }}$ distances (approximately $1.3 \AA$ ) in comparison to those of the smaller Cp ligands (appr. 1.7 ̊). Similar observations have been reported for other trometcenes. ${ }^{21}$ The substituents of the monosubstituted tromancenium salts, either in the 1-position (10) or the 8-position $(\mathbf{1 1}, \mathbf{1 8}, \mathbf{1 9})$, have no appreciable effect on the structural metrics, so that they do not differ from parent 9, as expected. However, 8-aminotromancenium (20) has a distorted structure with a slightly elongated $\mathrm{Mn} 1-\mathrm{C} 7$ bond

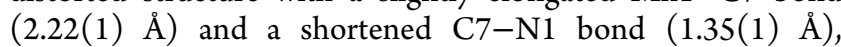
indicative of partial iminiumfulvene character, as it was already noted for the aminocobaltocenium ion. ${ }^{8 \mathrm{~b}}$ This is also in line with ${ }^{1} \mathrm{H} /{ }^{13} \mathrm{C} /{ }^{55} \mathrm{Mn}$ NMR solution data (vide supra).

Photoelectron spectroscopy (XPS) was performed on all six tromancenium salts in order to gain more insight on their electronic structures. In principle, cycloheptatrienyl is a quite interesting ligand whose three closed-shell configurations $\mathrm{C}_{7} \mathrm{H}_{7}{ }^{+}$(monocationic tropylium, $6 \pi$-electrons, Hückelaromatic), $\mathrm{C}_{7} \mathrm{H}_{7}^{-}$(monoanionic, $8 \pi$-electrons, anti-Hückelaromatic), or $\mathrm{C}_{7} \mathrm{H}_{7}{ }^{3-}$ (trianionic, $10 \pi$-electrons, Hückelaromatic) will impart corresponding different formal oxidation states to the coordinated metal center. In published XPS spectra of $\mathrm{Mn}(0)$ species, the $2 \mathrm{p}_{3 / 2}$ peak is located at $638.7 \mathrm{eV}$, whereas it is shifted to $641.4 \mathrm{eV}$ in complexes of $\mathrm{Mn}$ (II). ${ }^{22}$ With $640.3 \mathrm{eV}$ (9), $640.5 \mathrm{eV}$ (11), $640.6 \mathrm{eV}$ (10), $640.6 \mathrm{eV}$ (18), and $641.3 \mathrm{eV}$ (19), respectively, the binding energies of the present tromancenium salts fall in between these values (Figure 3, Supporting Information). Due to its electronegativity, the bromine substituent of 19 withdraws electron density from the metal center, resulting in a shift of the $2 \mathrm{p}_{3 / 2}$ signal toward the oxidation state +2 . For the amino-substituted

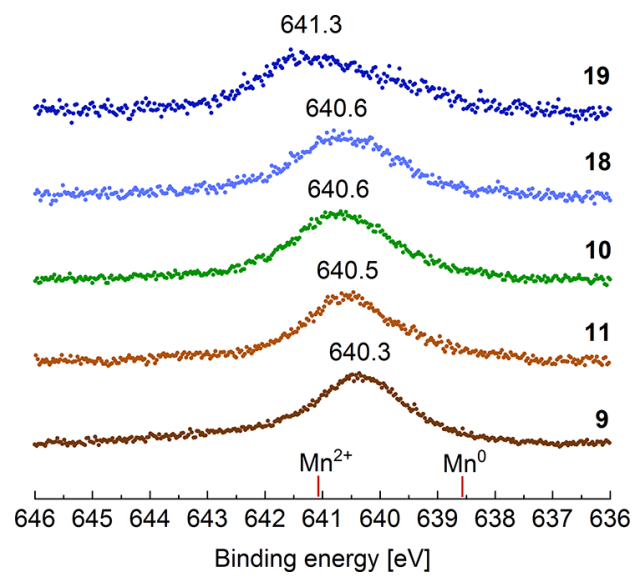

Figure 3. Stack of baseline-corrected XPS spectra of the Mn 2 $\mathrm{p}_{3 / 2}$ region of tromancenium salts $9-11,18$, and 19, including characteristic peak positions for $\mathrm{Mn}^{0}$ and $\mathrm{Mn}^{2+}$.

complex 20, the XPS spectrum of the $2 p$ region of manganese is of poor quality, most likely due to decomposition during the measurement, preventing in this case to determine the oxidation state of the metal center. Overall, our XPS spectra clearly indicate that the manganese center of tromancenium salts is best described by the oxidation state +1 , thereby assigning the cycloheptatrienyl ligand a cationic tropylium structure $\mathrm{C}_{7} \mathrm{H}_{7}{ }^{+}$. In contrast, early transition metal (Cht)M(Cp) sandwich complexes, $\mathrm{M}=\mathrm{Ti}, \mathrm{Zr}, \mathrm{Hf}{ }^{3}$ contain cycloheptatrienyl ligands that are more adequately described as trianionic $\mathrm{C}_{7} \mathrm{H}_{7}{ }^{3-}$ ligands, thereby attributing an oxidation state of +4 to $\mathrm{Ti}, \mathrm{Zr}$ and $\mathrm{Hf}$ in these compounds. ${ }^{3}$

Electrochemistry. Before turning to the redox properties of the cationic tromancenium complexes, we will briefly summarize those of the titanium, vanadium, and chromium congeners troticene, trovacene, and trochrocene (Table 2). Their valence electron counts of $16(\mathrm{Ti}), 17(\mathrm{~V})$, and $18(\mathrm{Cr})$ are reflected according to differences in electronic configurations and orbital occupancies ranging from $\mathrm{e}_{2}{ }^{4} \mathrm{a}_{1}{ }^{0}$ (Ti) to $\mathrm{e}_{2}{ }^{4} \mathrm{a}_{1}{ }^{1}(\mathrm{~V})$ and $\mathrm{e}_{2}{ }^{4} \mathrm{a}_{1}{ }^{2}(\mathrm{Cr})$. The Ti congener undergoes oneelectron reduction at $-2.70 \mathrm{~V}$. While being sufficiently stable in THF at $-20{ }^{\circ} \mathrm{C}$ to be characterized by EPR and UV/vis spectroscopy, the resulting anion is highly reactive at room temperature and gives rise to a chemical follow product. The latter oxidizes at a less cathodic potential of $-2.47 \mathrm{~V}$ to regenerate the starting material. The authors assumed a reversible hapticity change of the cycloheptatrienyl ligand to account for the overall square-scheme (or box) mechanism. Oxidation of this complex is chemically irreversible under all conditions and leads to rapid electrode passivation. ${ }^{23}$ The 17 valence-electron trovacene can be oxidized and reduced reversibly at $E_{1 / 2}=-0.23 \mathrm{~V}$ or $E_{1 / 2}=-3.04 \mathrm{~V}$ to generate a persistent cation and anion, respectively. ${ }^{24}$ Further oxidation at ca. $+0.61 \mathrm{~V}$ occurs as two overlapping anodic peaks and results in rapid degradation to unknown products. Trochrocene, which shares its $18 \mathrm{VE}$ count with the present tromancenium ions, reduces at ca. $-3.38 \mathrm{~V}$ to generate, after proton atom abstraction from the $\mathrm{NBu}_{4}{ }^{+}$cation of the supporting electrolyte, the neutral cycloheptatriene complex $\left(\eta^{6}-\mathrm{C}_{7} \mathrm{H}_{8}\right)$ $\left(\eta^{5}-\mathrm{C}_{5} \mathrm{H}_{5}\right) \mathrm{Cr}^{24 \mathrm{~b}}$ Quite interestingly, this latter complex, on exposure to a potassium mirror, (re)generates the trochrocene anion, which is also directly formed on reduction of trochrocene in the complete absence of a proton source. ${ }^{25}$ Its associated radical cation, which is formed at a half-wave 
Table 2. Redox Potentials of the Tromancenium Ions of This Study and the Parent Troticene, Trovacene and Trochrocene ${ }^{a, b}$

\begin{tabular}{|c|c|c|c|c|}
\hline $\operatorname{compd}^{b}$ & $E_{\mathrm{ox}}$ & $E_{\text {red }}$ & solvent & further redox processes \\
\hline$[(\mathrm{Cht}) \mathrm{Mn}(\mathrm{Cp})]^{+}(\mathbf{9})$ & $+0.70^{c}$ & $-1.61^{d}$ & DMF & associated reduced form gives rise to a chemical follow product, which oxidizes at $-0.52 \mathrm{~V}$ \\
\hline $\begin{array}{l}\left.\left({ }^{\mathrm{Me}} \mathrm{Cht}\right) \mathrm{Mn}(\mathrm{Cp})\right]^{+} \\
(\mathbf{1 0})\end{array}$ & $+0.69^{c}$ & $-1.62^{d}$ & DMF & associated reduced form gives rise to a chemical follow product, which oxidizes at $-0.55 \mathrm{~V}$ \\
\hline$\left[(\mathrm{Cht}) \mathrm{Mn}\left(\mathrm{Cp}^{\mathrm{Me}}\right)\right]^{+}$ & $+0.68^{c}$ & $-1.66^{d}$ & DMF & associated reduced form gives rise to a chemical follow product, which oxidizes at $-0.54 \mathrm{~V}$ \\
\hline $\begin{array}{l}{[(\mathrm{Cht})} \\
\left.\operatorname{Mn}\left(\mathrm{Cp}^{\mathrm{COOMe}}\right)\right]^{+} \\
(\mathbf{1 8})\end{array}$ & $+0.88^{c}$ & $-1.46^{d}$ & $\mathrm{CH}_{3} \mathrm{CN}$ & $\begin{array}{l}\text { associated reduced form gives a chemical follow product, which oxidizes at }-0.44 \mathrm{~V} \text {; further irreversible } \\
\text { reduction peak at }-2.50 \mathrm{~V}\end{array}$ \\
\hline $\begin{array}{l}{\left[(\mathrm{Cht}) \mathrm{Mn}\left(\mathrm{Cp}^{\mathrm{Br}}\right)\right]^{+}} \\
(\mathbf{1 9})\end{array}$ & $+0.93^{d}$ & $-1.49^{e}$ & $\mathrm{DMF}$ & associated reduced form gives rise to a chemical follow product, which oxidizes at $-0.31 \mathrm{~V}$ \\
\hline $\begin{array}{l}{\left[(\mathrm{Cht}) \mathrm{Mn}\left(\mathrm{Cp}^{\mathrm{NH} 2}\right)\right]^{+}} \\
(\mathbf{2 0})\end{array}$ & +0.40 & -1.33 & $\mathrm{DMF}$ & additional oxidation wave at $+0.65 \mathrm{~V}$ and reduction peaks at $-1.84 \mathrm{~V}$ and $-3.16 \mathrm{~V}$ \\
\hline$[(\mathrm{Cht}) \mathrm{Ti}(\mathrm{Cp})]$ & $-0.01^{d}$ & $-2.70^{e}$ & THF & $\begin{array}{l}\text { associated reduced form gives rise to a chemical follow product, which oxidizes at }-2.47 \mathrm{~V} \text { and } \\
\text { regenerates the starting complex }\end{array}$ \\
\hline$\left[(\mathrm{Cht}) \mathrm{Ti}\left(\mathrm{Cp}^{*}\right)\right]$ & $-0.18^{d}$ & $-2.78^{e}$ & THF & associated reduced form gives rise to a chemical follow product, which oxidizes at $-2.56 \mathrm{~V}^{23 \mathrm{~b}}$ \\
\hline$[(\mathrm{Cht}) \mathrm{V}(\mathrm{Cp})]$ & -0.23 & -3.04 & DME & further, chemically irreversible $2 \mathrm{e}^{-}$oxidation at ca. $+0.61 \mathrm{~V}^{23 \mathrm{~b}}$ \\
\hline$[(\mathrm{Cht}) \mathrm{Cr}(\mathrm{Cp})]$ & -1.10 & $-3.38^{e}$ & $\mathrm{DME}$ & $\begin{array}{l}\text { associated anion rapidly forms }\left(\eta^{6}-\mathrm{C}_{7} \mathrm{H}_{8}\right) \mathrm{CrCp} \text { by proton abstraction; further oxidation as a chemically } \\
\text { irreversible process at }+1.10 \mathrm{~V}^{23 \mathrm{~b}}\end{array}$ \\
\hline
\end{tabular}

${ }^{a}$ Potentials are given in volts and are calibrated against the $\mathrm{Cp}_{2} \mathrm{Fe}^{0 /+}$ redox couple. ${ }^{b} \mathrm{Cht}=\eta^{7}$-cycloheptatrienyl, $\mathrm{Cp}=\eta^{5}$-cyclopentadienyl. ${ }^{c} \mathrm{Half}-$ wave potential of a chemically only partially reversible process. ${ }^{d}$ Peak potential of a chemically irreversible redox process. ${ }^{e}$ Potential calibration against the $\mathrm{Cp}_{2} \mathrm{Fe}^{0 /+}$ redox couple. ${ }^{24 \mathrm{c}}$

potential of $-1.10 \mathrm{~V}$, is stable under even less stringent conditions. ${ }^{25,26}$ Like for trovacene, further oxidation occurs as a chemically irreversible two-electron process at a much more positive peak potential of $+1.10 \mathrm{~V}^{24 \mathrm{~b}}$

The electrochemistry on the present tromancenium ions was assessed in DMF and $\mathrm{CH}_{3} \mathrm{CN}$ as solvents, using $0.1 \mathrm{M} \mathrm{NBu}_{4}^{+}$ $\mathrm{PF}_{6}^{-}$as the supporting electrolyte. $\mathrm{CV}$ responses in these solvents are in most cases rather similar (see Table 2 and Figure 4), with some exceptions (see below). The choice of the

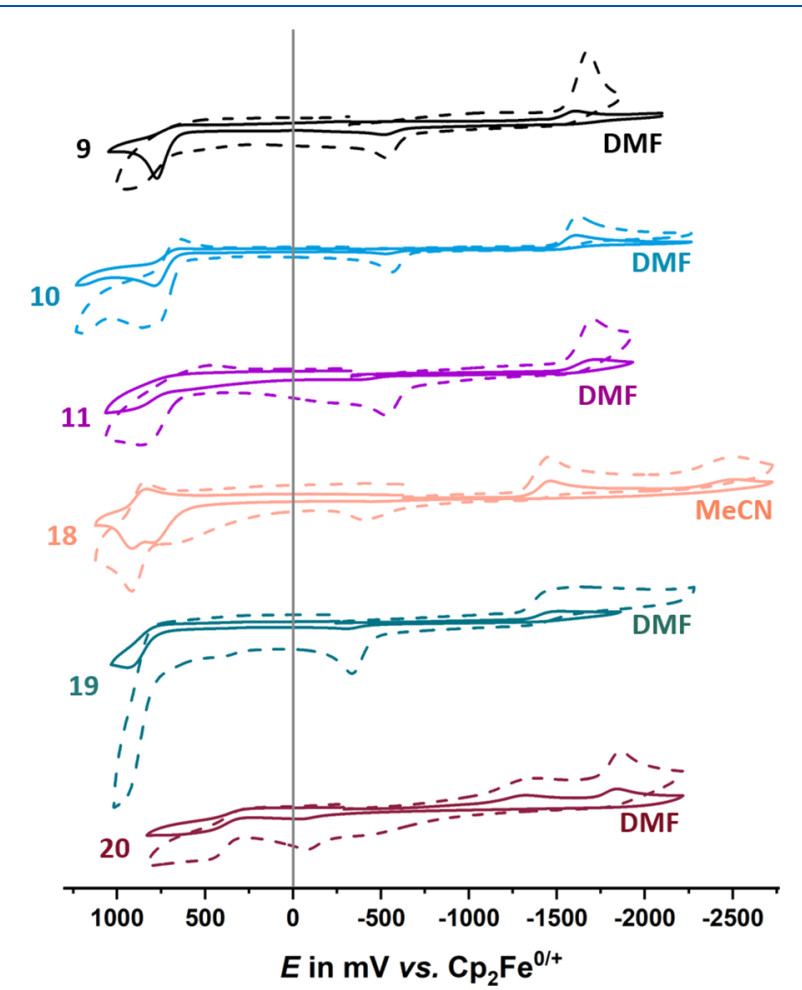

Figure 4. Cyclic voltammograms of the tromancenium ions 9-11 and 18-20 in DMF or MeCN $\left(0.1 \mathrm{M} \mathrm{NBu}_{4}{ }^{+} \mathrm{PF}_{6}{ }^{-}\right)$on a glassy carbon working electrode at sweep rates $v$ of 0.1 (solid line) and $0.6 \mathrm{~V} \mathrm{~s}^{-1}$ (dotted line). working electrode proved to be critical. Platinum led to severe electrode passivation even upon a single scan, with often erratic shifts of peak potentials. Better results were obtained on glassy carbon (for a comparison of $\mathbf{1 0}$ at different scan rates, see Figure S44), but even then, severe electrode passivation was noted. This required wiping of the electrode surface after every scan and frequent repolishing with diamond pastes after only a few scans in order to obtain reproducible results.

Considering that trochrocene and the tromancenium ions share the same valence electron count of 18 , but differ by their outer charge, one would expect an anodic shift of all redox processes for the manganese congener, but overall similar redox properties. This proved to be the case, as the half-wave/ peak potentials for tromancenium oxidation/reduction exhibit a sizable anodic shift of ca. $1.8 \mathrm{~V}$ compared to those of neutral trochrocene (see Table 2).

Figure 5 and Figure S45 illustrate the typical appearance of the cyclic voltammograms studied in this work as exemplified

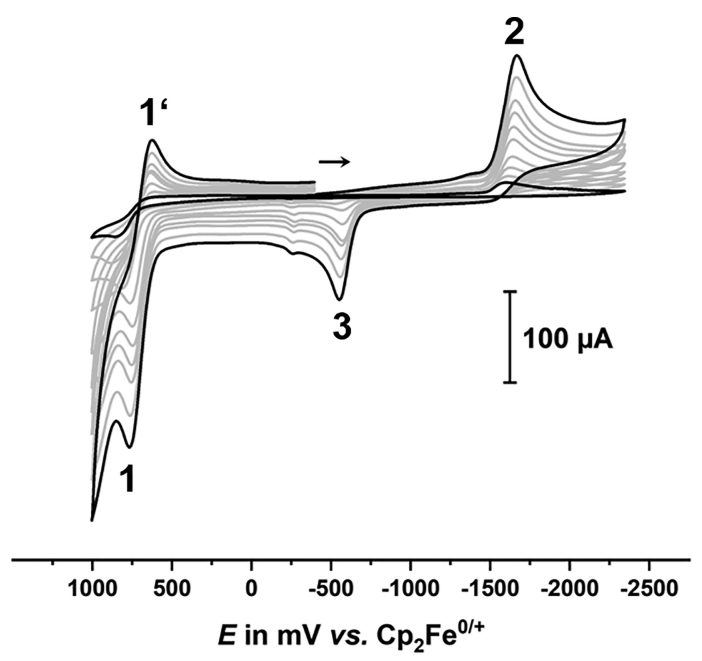

Figure 5. Cyclic voltammograms of the parent tromancenium ion 9 $(4 \mathrm{mM})$ in $\mathrm{DMF} / 0.1 \mathrm{M} \mathrm{NBu}_{4}{ }^{+} \mathrm{PF}_{6}{ }^{-}$on a glassy carbon working electrode at rt and at sweep rates $v$ of 0.025 to $2.0 \mathrm{~V} \mathrm{~s}^{-1}$. 
with the parent tromancenium ion 9. All tromancenium ions undergo an oxidation, denoted as peaks $1 / 1^{\prime}$ (cf. $E_{\text {ox }}$ in Table 2 ) in Figure 4, and an irreversible reduction (cf. $E_{\text {red }}$ in Table 2 ), marked as peak 2 in Figure 5. Both processes involve the transfer of a single electron as associated from peak widths and the similar peak currents. Anodic oxidation is (close to) irreversible at low seep rates but becomes chemically partially reversible at faster sweep rates. Scan rates of $0.4 \mathrm{~V} \mathrm{~s}^{-1}$ or more are required in order to observe the associated cathodic return peak, even for the most electron-rich amino-substituted congener (see Figure 4). No additional peak/wave ascribable to a follow product was observed under conditions, where the oxidation was largely irreversible.

Reduction gives rise to an electroactive follow product, which oxidizes ca. $1.1 \mathrm{~V}$ anodic of the original reduction peak (denoted as peak 3 in Figure 5) and provides no associated cathodic return peak on scan reversal (see Figure S46). In agreement with its formation during the reductive scan, peak 3 is only observed after prior reduction as shown in Figure S46. Attempts to investigate whether the follow product reverts to the starting tromancenium compound on reoxidation were thwarted by excessive electrode fouling as it is exemplarily shown in Figure S47. Chemical irreversibility of the initial reduction also prevails on lowering $T$ to $-40{ }^{\circ} \mathrm{C}$ with even more severe problems of electrode passivation. A representative set of scans at variable $T$ is shown as Figure S48.

In order to possibly gain further insights on the follow product formed after reduction, complex 9 was chemically reduced with 1.2 equiv of decamethylcobaltocene and $T$ dependent EPR spectra were recorded in DMF as shown in Figure S49. As presented on the left of Figure 6, the EPR spectrum at $20^{\circ} \mathrm{C}$ could be simulated with hyperfine couplings to one ${ }^{55} \mathrm{Mn}$ nucleus $(A=265 \mathrm{G})$.

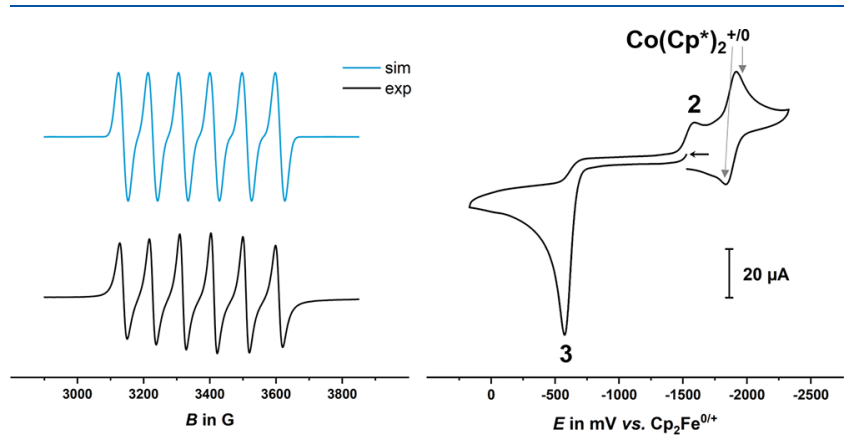

Figure 6. (Left) EPR spectrum (black) and simulation (blue) of chemically reduced 9 prepared by reaction with 1.2 equiv of decamethylcobaltocene at $20{ }^{\circ} \mathrm{C}$ in DMF solution. (Right) CV of a chemically reduced sample of 9 in DMF/0.1 $\mathrm{M} \mathrm{NBu}_{4}{ }^{+} \mathrm{PF}_{6}{ }^{-}$at a glassy carbon working electrode and at a sweep rate $v$ of $0.2 \mathrm{~V} \mathrm{~s}^{-1}$.

When the chemically reduced sample was analyzed by cyclic voltammetry, the wave assignable to the electrogenerated follow product now appeared as a chemically irreversible forward wave (peak 3 in Figure 6, right), and the original reduction peak (peak 2 in Figure 6, right) was observed again. This peak was absent if the scan was clipped before scanning through peak 3. This experiment suffered, however, from severely absorptive behavior and particularly problematic electrode passivation. Nevertheless, these results support that the $9 / 9^{-}$redox system and the electroactive product, which is generated from $\mathbf{9}^{-}$, constitute an overall (at least partially) reversible redox system, which obeys an overall "square scheme" mechanism. ${ }^{27}$

In order to also probe for a higher order reaction (e.g., a dimerization), we monitored the ratio of the peak currents associated with the chemical follow peak $3\left(i_{\mathrm{pf}, \mathrm{a} 3}\right)$ and of the initial cathodic reduction peak $2\left(i_{\mathrm{p}, \mathrm{c} 2}\right)$ at three different analyte concentrations and over a range of different sweep rates (for results on complex 9, see Figures S50-S51). At identical sweep rates, the ratio $i_{\mathrm{pf}, \mathrm{a} 3} / i_{\mathrm{p}, \mathrm{c} 2}$ is, within the error margins, independent of the analyte concentration $c$. This argues against such a possibility, leaving hydride abstraction of the ensuing neutral radical as a plausible scenario.

Methyl substitution at either the cycloheptatrienylium (10, right of Figure 7) or the cyclopentadienide (11, left of Figure
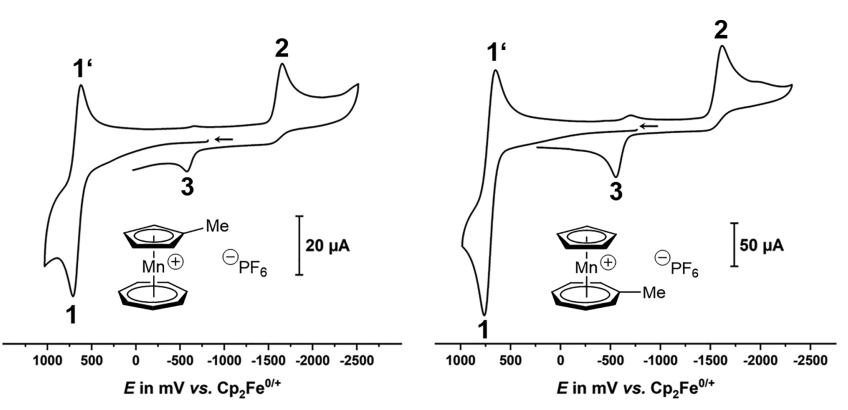

Figure 7. Cyclic voltammograms of the isomeric methyltromancenium ions 11 (left) and 10 (right) in DMF/0.1 $\mathrm{M} \mathrm{NBu}_{4}{ }^{+} \mathrm{PF}_{6}{ }^{-}$on a glassy carbon working electrode at $\mathrm{rt}$ and at $v=0.6 \mathrm{~V} \mathrm{~s}^{-1}$.

7) ligand has the expected effect of shifting the reduction, and to a minor extent, the oxidation potential to more cathodic values (cf. Table 2). For the reduction of compound 11, the shift induced by methyl substitution at the cyclopentadienide ligand comes close to that of -0.05 to $-0.06 \mathrm{~V}$ observed in methylferrocene as compared to ferrocene. ${ }^{28}$ It is notably larger compared to that of substitution at the seven-membered ring in $\mathbf{1 0}$ (Table 2). In both complexes, 10 and 11, methyl substitution slightly stabilizes the associated radical cations as shown by the enhanced currents of the cathodic return peak $1^{\prime}$ when compared to the parent tromancenium ion (compare Figures 5 and 7).

Further modification by replacing the methyl substituent of compound 11 with an electron acceptor or a stronger donor has concomitant consequences on the redox potentials. 8Carboxymethyltromancenium 18 thus exhibits anodic shifts for both processes of 0.18 or $0.15 \mathrm{~V}$, respectively. Scanning past the primary reduction peak reveals another irreversible reduction at ca. $-2.48 \mathrm{~V}(-2.50 \mathrm{~V}$ in $\mathrm{MeCN})$, which probably corresponds to the further reduction of the ester functionality within the electrogenerated follow product (cf. Figure S56), which reveals itself by an anodic follow peak at $-0.44 \mathrm{~V}$ (Figure 4 and top of Figure S57). Oxidation of 8bromotromancenium 19 constitutes a chemically irreversible process under all applied conditions (cf. Table 2 and Figures S58-59). Reduction is likewise ill-behaved and gives rise to several small cathodic peaks on the reverse scan (see right side of Figure S59). The oxidation and reduction potentials of the 8-aminotromancenium ion, 20, the most electron-rich congener of this series, are by ca. $0.3 \mathrm{~V}$ more cathodic than that of the parent tromancenium ion. We also note an additional oxidation wave at $+0.65 \mathrm{~V}$ as well as an additional reduction peak at $-3.16 \mathrm{~V}$ (cf. Figure S60), close to the 
cathodic discharge limit of the DMF electrolyte. Representative CV scans are shown as Figures S60 and S61.

Quantum Chemical Calculations. To further characterize the chemical nature and the bonding of tromancenium 9, quantum chemical studies were performed to gain an understanding of its (electronic) structure. Geometry optimizations with various density functionals revealed that the $\eta^{5}$ coordination of the cyclopentadienyl and the $\eta^{7}$ coordination of the cycloheptatrienyl ligands-as evident in the crystal structure-remains intact in the gas phase and in implicit DMSO. C-C double bonds are completely delocalized over the 5-membered ring, while there are small bond-length alternations in the 7 -membered ring. The distance of the cyclopentadienyl ring to $\mathrm{Mn}$ is at around $1.7 \AA$ and thereby around $0.4 \AA$ longer than that of the cycloheptatrienyl ring. Overall, the optimized structures are similar to the crystal structure and show little dependence on the employed density functional (compare also Table S1). Analysis of Hirshfeld partial charges indicate that the positive charge of the cationic species 9 is allocated at the Mn center (see Table S3).

To shed light on the electronic structure of 9, frontier molecular orbitals were investigated. As visible from Figure 8,

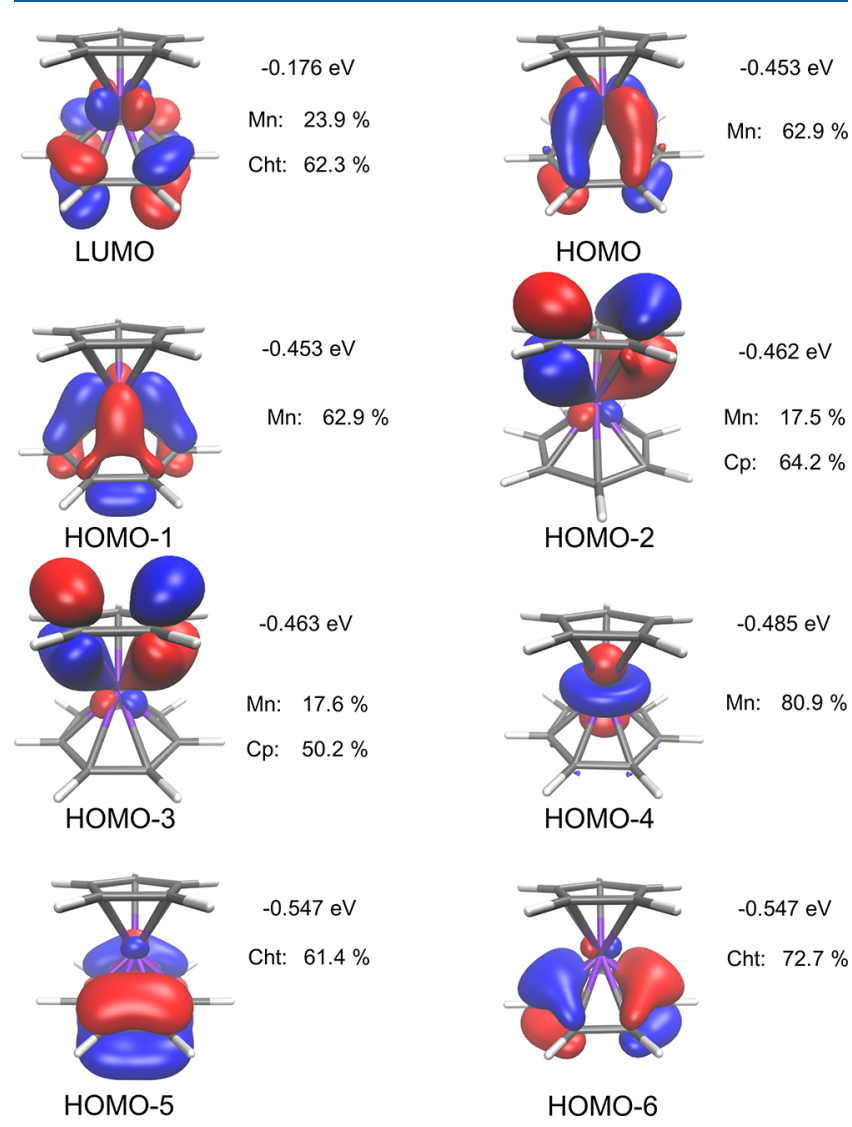

Figure 8. Frontier molecular orbitals calculated with PBE0-D3/def2TZVPP. An isosurface of 0.05 arbitrary units was used for visualization.

both the highest occupied molecular orbital (HOMO) as well as the lowest unoccupied molecular orbital (LUMO) are centered at the metal or at the metal and the cycloheptatrienyl ring, but not on the cyclopentadienyl ring. This trend is consistent for various density functionals (compare Figures S39 and S40). In fact, the first molecular orbital that has notable contributions from the cyclopentadienyl ligand is
HOMO-2. These findings suggest that redox or chemical reactions take place either at the $\mathrm{Mn}$ center or at the 7membered ring, but not at the $\mathrm{Cp}$ ligand. This is in line with our experimental electrochemical studies (vide supra).

Calculated Brønstedt acidities in dimethyl sulfoxide (modeled as implicit solvent with $\varepsilon=47.2$ ) are very low with the cyloheptatrienyl ligand being slightly more acidic than the cyclopentadienyl ligand $\left[\mathrm{p} K_{\mathrm{a}}(\mathrm{Cht})=42( \pm 1), \mathrm{p} K_{\mathrm{a}}(\mathrm{Cp})=\right.$ $44( \pm 2)]$. For comparison, the calculated $\mathrm{p} K_{\mathrm{a}}$ of cobaltocenium hexafluoridophosphate is $38.5( \pm 2) .^{8 \mathrm{~d}}$

When we reduced 9 in an in silico experiment to the neutral 19-electron "tromancene" species $\mathbf{9}^{-}$, we observed a distinct behavior. While the cyclopentadienyl ligand kept its $\eta^{5}$ coordination, the hapticity of the cyloheptatrienyl heavily depends on the employed density functional-ranging from $\eta^{4}$ to $\eta^{7}$ (Table S2). In addition, the energy splitting between the doublet and the quartet states also showed a dependence on the density functional with PBE0-D3 and $\omega \mathrm{B} 97 \mathrm{x}-\mathrm{d}$, predicting the quartet state to be more stable by $\Delta E_{\mathrm{d}-\mathrm{q}}=\mathrm{ca} .50 \mathrm{~kJ} / \mathrm{mol}$ and $\Delta G_{\mathrm{d}-\mathrm{q}}{ }^{298 \mathrm{~K}}=\mathrm{ca} .60 \mathrm{~kJ} / \mathrm{mol}$, whereas BP86-D3 favors the doublet state (compare Table S2), which is in line with previous findings. ${ }^{29} \mathrm{~A}$ recent combined experimental and computational benchmark study on a series of related metallocenes found the $\omega \mathrm{B} 97 \mathrm{x}-\mathrm{d}$ density functional to yield accurate results for the spin-state energetics of a related $\left[\mathrm{MnCp}_{2}\right]$ compound. ${ }^{30}$ Hence, we assume these calculations to be more accurate and surmise the quartet state to be the more stable one here. Regardless of the differences in the predicted spin-state splitting and the different coordination pattern of the cycloheptatrienyl ligand, the spin density is in all instances located at the metal center (Figures S65-S67). Analysis of the Hirshfeld partial charges exemplary calculated with the PBE0 density functional revealed a positively charged metal center (Table S3).

\section{SUMMARY}

A custom-made high-power LED photoreactor was proven to be highly advantageous in comparison to standard photochemical methodology for the convenient and rapid synthesis of six tromancenium salts. Substitution of the three carbonyl ligands of cymantrenes under blue light irradiation with cycloheptatrienes followed by oxidation/hydride removal with tritylium hexafluoridophosphate afforded the parent tromancenium hexafluoridophosphate $\left.\left[\eta^{7}-\mathrm{C}_{7} \mathrm{H}_{7}\right) \mathrm{Mn}\left(\eta^{5}-\mathrm{C}_{5} \mathrm{H}_{5}\right)\right] \mathrm{PF}_{6}$ and five monosubstituted derivatives containing methyl, methoxycarbonyl, bromo, and amino substituents in $97-10 \%$ yield, dependent on the photochemical stability of the substituents.

Tromancenium salts are 18-valence-electron, air-stable, polar compounds of red color, soluble in common polar organic solvents and also in water. Full spectroscopic characterization by HRMS, IR, UV-vis, and ${ }^{1} \mathrm{H} /{ }^{13} \mathrm{C}$ NMR, and notably also by ${ }^{55} \mathrm{Mn}-\mathrm{NMR}$, is reported. Single-crystal analyses show typical sandwich metal complex structures with parallel displaced cycloheptatrienyl and cyclopentadienyl rings and more or less identical manganese-carbon bond lengths for the $\mathrm{Mn}-$ cycloheptatrienyl and $\mathrm{Mn}$-cyclopentadienyl carbon bonds. The electronic structures of tromancenium salts are best described by a manganese center of formal oxidation state +1 coordinated to a $6 \pi$-electron cyclopentadienide and a $6 \pi$ electron tropylium ligand, as shown by manganese photoelectron spectroscopy.

Detailed quantum chemical calculations of the parent tromancenium hexafluoridophosphate indicate that metal- 
ligand bonding is distinctly weaker for the cycloheptatrienyl ligand in comparison to that of the cyclopentadienyl ligand. Both the HOMO (highest occupied molecular orbital) and the LUMO (lowest unoccupied molecular orbital) are metal and cycloheptatrienyl-ligand centered, indicating that redox processes or electrophilic and nucleophilic chemical reactions will occur either metal-based or at the seven-membered ring, but not on the cyclopentadienyl ligand.

Electrochemically, tromancenium salts can be oxidized to the dication and reduced to the neutral species at rather low potentials, although not reversibly. The half-wave/peak potentials respond to the inductive effects of the substituents at the cyclopentadienyl or the cycloheptatrienyl ligands. The product generated by reduction of the parent complex was studied in more detail. Chemical reduction yielded an EPR active species with a resolved hyperfine splitting to one ${ }^{55} \mathrm{Mn}$ nucleus. The latter species regenerates at least partially the parent complex on reoxidation, thus establishing an overall square scheme mechanism.

With this work we show that the long neglected and forgotten tromancenium complexes are readily available by photochemical synthesis with modern high-power LED light sources. In a broader context, LED-based photochemistry will most likely replace standard photochemical methodology and will become a fertile area of organometallic, inorganic and organic synthetic chemistry.

\section{EXPERIMENTAL SECTION}

General Procedures. Standard methods and procedures of organic/organometallic synthesis, spectroscopic characterization and single-crystal structure XRD analysis were performed. ${ }^{1} \mathrm{H},{ }^{13} \mathrm{C}$, and ${ }^{55} \mathrm{Mn}$ NMR spectra were recorded at $25{ }^{\circ} \mathrm{C}$ on a Bruker Avance DPX 300 NMR spectrometer, and signals were referenced internally against ${ }^{1} \mathrm{H} /{ }^{13} \mathrm{C}$ residual solvent peaks or externally $\left({ }^{55} \mathrm{Mn}\right)$ against a saturated $\mathrm{KMnO}_{4} / \mathrm{D}_{2} \mathrm{O}$ solution. Mass spectrometric data were measured on a Thermo Finnigan Q Exactive Orbitrap spectrometer, IR spectra were recorded on a Bruker ALPHA IR spectrometer, UV-vis spectra were measured on a PerkinElmer Lambda XLS+ spectrometer, singlecrystal X-ray diffraction data were collected on a Bruker D8 Quest diffractometer with graphite-monochromated $\mathrm{Mo}-\mathrm{K}_{\alpha}$ radiation $(\lambda=$ $0.71073 \AA$ ) , and structures were solved by direct methods.

Cyclic voltammetry was performed as described recently. ${ }^{8 \mathrm{~d}} \mathrm{~T}$ dependent (thermostat with temperature controller $\mathrm{HO} 3$ using liquid nitrogen) electron paramagnetic resonance (EPR) spectroscopy was performed on a X-band spectrometer MiniScope MS5000 by Magnettech $\mathrm{GmbH}$ in combination with the program ESR Studio 1.63.0. The EPR sample was prepared by chemical reduction of complex 9 with 1.2 equiv of decamethylcobaltocene in DMF inside a nitrogen glovebox.

For XPS measurements, the powders were freshly grounded before the measurement under nitrogen atmosphere in a mortar and applied as thin layer on an adhesive copper foil which was then transferred into the vacuum system without air exposure. Measurements were performed on a multichamber ultrahigh vacuum system at a pressure of $5 \times 10^{-10}$ mbar using a Phoibos 100 hemispherical analyzer (Specs). As the excitation source, an $\mathrm{Al}-\mathrm{K}_{\alpha}$ anode was used ( $\mathrm{h} \cdot \nu=$ $1486.6 \mathrm{eV}$, probing depth $\sim 10 \mathrm{~nm}$ ). Due to charging effects during measurements caused by the low conductivity of the powder samples, the binding energy scale as measured by XPS was shifted by a few electron volts for the different samples; to account for this, the binding energies were corrected such that adventitious carbon is positioned at $284.8 \mathrm{eV}$. Upon extended X-ray exposure, some samples showed oxidation and decomposition effects. Therefore, data collect times were kept short (around $20 \mathrm{~min}$ ) to ensure that only the pristine material is probed. To achieve sufficient count rates, a rather high pass energy of $40 \mathrm{eV}$ was used.
Starting Materials. Chemicals were obtained commercially and used as received. Note: If cymantrene, $\mathrm{CpMn}(\mathrm{CO})_{3}$, is obtained commercially, its quality has to be critically tested by TLC, PXRD and ${ }^{55} \mathrm{Mn}$-NMR. Recently ordered batches from various vendors with a specified purity of $98 \%$ had an actual cymantrene content of only $37 \%$ in admixture with $\mathrm{Mn}_{2}(\mathrm{CO})_{10}$, indicating that these chemicals originated from the same primary source. $\mathrm{Mn}_{2}(\mathrm{CO})_{10}$ is the starting material in cymantrene synthesis and has similar physical properties (appearance, color, sublimation point), it can only be separated from cymantrene by chromatography on alumina with pentane as eluent. Hence, we recommend synthesis of cymantrene freshly. ${ }^{19}$ 7Methylcyclohepta-1,3,5-triene, ${ }^{31}$ methoxycarbonylcymantrene, ${ }^{12}$ bromocymantrene, ${ }^{13}$ and aminocymantrene ${ }^{15}$ were prepared according to literature.

Photochemical Syntheses. Caution. In all photochemical syntheses with high-power light sources, appropriate eye protection or only an apparatus with a completely covered setup during irradiation is mandatory. Photochemical syntheses were performed in Schlenk vessels equipped with a reflux condenser under strict exclusion of $\mathrm{O}_{2}$ in dry, purified, freeze-thawed, Ar-saturated solvents and starting materials using a custom-made high-power LED-reactor "Solar Light Lab Luminaire" (Figure 9) developed in collaboration



Figure 9. "Solar Light Lab Luminaire" photochemical apparatus with removed cover.

with the Austrian company Bartenbach. ${ }^{10}$ This apparatus allows irradiation of chemical solutions on a $5-100 \mathrm{~mL}$ scale in a controlled manner with monochromatic light, ranging from $360 \mathrm{~nm}$ with $260 \mathrm{~W}$ electrical power up to $535 \mathrm{~nm}$ with $370 \mathrm{~W}$ electrical power or with polychromatic cool white, respectively. Thereby, selective photochemical activation with either UV, blue, green, or white light is possible with significantly reduced irradiation times of less than 30 min compared to $8 \mathrm{~h}$ or more commonly used in a traditional fallingfilm photoreactor with medium-pressure mercury lamps. The LED photoreactor is also equipped with a photodiode that allows measuring of the photon flux in the center of the apparatus corresponding to the volume of the solution, thereby allowing calculation of the quantum yield. 
DFT Calculations. A starting structure of 9 was derived from the existing crystal structure and subjected to quantum chemical studies with dispersion corrected density functional theory calculation in the gas phase and in DMSO modeled as implicit solvent with $\varepsilon=47.2 .9$ was optimized with the hybrid PBE0 density functional, ${ }^{32}$ the pure BP86 density functional, ${ }^{33}$ and the range-separated hybrid density functional $\omega \mathrm{B} 97 \mathrm{x}-\mathrm{d}^{34}$ in combination with the triple- $\zeta$ def2-TZVPP basis set. ${ }^{35}$ For speed-up, the resolution-of-identity technique was used. ${ }^{36}$ Empirical dispersion corrections with Becke-Johnson damping were added in the case of PBE0 and BP86. ${ }^{37}$ Bulk solvent effects of DMSO were accounted for with the Conductor-Like Screening Model (COSMO), ${ }^{38}$ where the solvent was described with a dielectric constant $\varepsilon=47.2 .9$ was considered in its closed-shell state only (i) because a singlet state is consistent with experimental observations and (ii) because the energies of the triplet states were found to be between 70 to $115 \mathrm{~kJ} / \mathrm{mol}$ higher in energy than the singlet state. Frontier molecular orbitals were calculated with PBE0 and BP86 and-for sake of comparison ${ }^{34}$-also with M05-2 $\mathrm{X}^{39} /$ def2-TZVPP. ${ }^{35}$ All frontier molecular orbitals were generated from single-point calculations on the PBE0-optimized structures and calculated with Gaussian 16 as it provided the contribution of the individual atoms to the respective orbitals. ${ }^{40} \mathrm{pK}_{\mathrm{a}}$ values were determined by a thermodynamic cycle as detailed in the Supporting Information. To obtain Gibbs free energies (for the calculation of $\mathrm{p} K_{\mathrm{a}}$ values), zeropoint energy and thermal corrections calculated with the rigid-rotor/ quasi-harmonic oscillator were added to the electronic energy. To increase the accuracy calculated frequencies were scaled with a factor of 0.9821 (PBE0), of 1.0181 (BP86), and of $0.9779(\omega \mathrm{B} 97 \mathrm{x}-\mathrm{d})^{41}$ and frequencies below $50 \mathrm{~cm}^{-1}$ were set to $50 \mathrm{~cm}^{-1}$. ${ }^{42}$ For the investigation of the reduced 19 -electron species $9^{-}$, spin-unrestricted calculations were carried out both in the doublet and in the quartet state. Partial charges were calculated according to Hirshfeld ${ }^{43}$ as the difference between the molecular and the atomistic charge density as implemented in Gaussian 16. ${ }^{40}$ Unless otherwise noted, all calculations were performed with the quantum chemical program package Turbomole. ${ }^{44}$ Structures were visualized with $\mathrm{PyMol}^{45}$ and VMD. ${ }^{46}$

$\eta^{7}$-Cycloheptatrienyl- $\eta^{5}$-cyclopentadienylmanganese (Tromancenium) Hexafluoridophosphate (9). A Schlenk flask, equipped with a reflux condenser and a bubbler, was charged with $0.200 \mathrm{~g}$ of cymantrene $(0.980 \mathrm{mmol}, 1.00$ equiv), $162 \mu \mathrm{L}$ of $1,3,5-$ cycloheptatriene $(1.470 \mathrm{mmol}, 1.50$ equiv), and $20 \mathrm{~mL}$ of dry heptane. The apparatus was then irradiated with blue light $(450 \mathrm{~nm})$ and $370 \mathrm{~W}$ for $15 \mathrm{~min}$ until no further carbon monoxide evolution was observed. Note: A successful reaction is indicated by a color change from yellow to red. Heptane was removed in vacuo. The intermediate highly air-sensitive -complex was dissolved in dichloromethane (abs) and cooled to $0{ }^{\circ} \mathrm{C}$. Tritylium hexafluoridophosphate $(0.570 \mathrm{~g}, 1.470 \mathrm{mmol}, 1.50$ equiv $)$ was added in one portion, and the solution was stirred for additional $30 \mathrm{~min}$ under exclusion of light. After precipitation with diethyl ether, the air stable crude product was filtered off and washed three times with $10 \mathrm{~mL}$ portions of diethyl ether. The crude product was dissolved with acetonitrile from the folded filter. The solvent was removed in vacuo and the solid residue was purified by a short column chromatography on neutral alumina with acetonitrile-diethyl ether (3:7). After yellow remains of nonpolar trityl are removed completely, tromancenium hexafluoridophosphate is eluted with acetonitrile, affording $\mathbf{9}$ as red crystals in $73.9 \%$ yield $(0.258 \mathrm{~g}, 0.724 \mathrm{mmol})$. An overall quantum yield of $1.5 \%$ was calculated. Compound 9 is air-stable and soluble in acetone, acetonitrile, and dimethyl sulfoxide. Mp: $246{ }^{\circ} \mathrm{C} .{ }^{1} \mathrm{H}$ NMR (300.1 $\left.\mathrm{MHz}, \mathrm{CD}_{3} \mathrm{CN}, \mathrm{ppm}\right): \delta=4.73(\mathrm{~s}, 5 \mathrm{H}, \mathrm{C} 8-12$ of $\mathrm{Cp}), 6.84(\mathrm{~s}, 7 \mathrm{H}$, $\mathrm{C} 1-7$ of Cht $).{ }^{13} \mathrm{C}$ NMR $\left(75.5 \mathrm{MHz}, \mathrm{CD}_{3} \mathrm{CN}, \mathrm{ppm}\right): \delta=78.3(\mathrm{C} 8-$ 12 of $\mathrm{Cp}$ ), 97.5 ( $\mathrm{C} 1-7$ of $\mathrm{Cht}) .{ }^{55} \mathrm{Mn}-\mathrm{NMR}\left(74.4 \mathrm{MHz}, \mathrm{CD}_{3} \mathrm{CN}\right.$, ppm): $\delta=271.0$. IR $\left(\mathrm{ATR}, \mathrm{cm}^{-1}\right): 3123\left(\nu_{\mathrm{C}-\mathrm{H}}\right), 3079\left(\nu_{\mathrm{C}-\mathrm{H}}\right), 1448$ $\left(\nu_{\mathrm{C}=\mathrm{C}}\right), 1428\left(\nu_{\mathrm{C}=\mathrm{C}}\right), 1016\left(\delta_{\mathrm{C}-\mathrm{H}}\right), 810\left(\nu_{\mathrm{P}-\mathrm{F}}\right), 554\left(\delta_{\mathrm{P}-\mathrm{F}}\right), 445$ $\left(\nu_{\text {metal-ring }}\right)$. HRMS (ESI pos, $\left.m / z\right): 211.0309\left(\left[\mathrm{M}-\mathrm{PF}_{6}\right]^{+}\right)$, calcd for $\mathrm{C}_{12} \mathrm{H}_{12} \mathrm{Mn}: 211.0314$. UV/vis $\left(\mathrm{CH}_{3} \mathrm{CN},[\mathrm{nm}]\right): \lambda_{\max 1}=278, \lambda_{\max 2}=$ 544. Single crystals of 9 were obtained via diffusion crystallization in acetonitrile out of diethyl ether at room temperature. Single-crystal analysis (Figure 2, Supporting Information).

$\eta^{7}$-Methylcycloheptatrienyl- $\eta^{5}$-cyclopentadienylmanganese (1-Methyltromancenium) Hexafluoridophosphate (10). Analogous to the synthesis of $\mathbf{9}$ described above, $\mathbf{1 0}$ was prepared starting from $0.275 \mathrm{~g}$ of cymantrene ( $1.350 \mathrm{mmol}, 1.00$ equiv), $210 \mu \mathrm{L}$ of 7 methylcyclohepta-1,3,5-triene (1.691 mmol, 1.25 equiv), and $10 \mathrm{~mL}$ of heptane (abs). Irradiation with blue light $(450 \mathrm{~nm})$ and $370 \mathrm{~W}$ for 15 min and subsequent reaction with tritylium hexafluoridophosphate $(0.655 \mathrm{~g}, 1.686 \mathrm{mmol}, 1.25$ equiv) afforded 1-methyltromancenium hexafluoridophosphate (10) as red crystals in $25.0 \%$ yield $(0.125 \mathrm{~g}$, $0.338 \mathrm{mmol})$ in a quantum yield of $5.3 \%$. Mp: $206{ }^{\circ} \mathrm{C} \mathrm{dec} .{ }^{1} \mathrm{H}$ NMR $\left(300.1 \mathrm{MHz}, \mathrm{CD}_{3} \mathrm{CN}, \mathrm{ppm}\right): \delta=2.80\left(\mathrm{~s}, 3 \mathrm{H}, \mathrm{CH}_{3}\right), 4.67(\mathrm{~s}, 5 \mathrm{H}$, $\mathrm{C} 8-12$ of $\mathrm{Cp}$ ), $6.70(\mathrm{~m}, 6 \mathrm{H}, \mathrm{C} 2-\mathrm{C} 7 \mathrm{of} \mathrm{Cht}) .{ }^{13} \mathrm{C} \mathrm{NMR}(75.5 \mathrm{MHz}$, $\left.\mathrm{CD}_{3} \mathrm{CN}, \mathrm{ppm}\right): \delta=26.4\left(\mathrm{CH}_{3}\right), 78.7(\mathrm{C} 8-12$ of $\mathrm{Cp}), 96.0(\mathrm{C} 2 / \mathrm{C} 7$ of Cht), 97.0 (C3/C6 of Cht), 97.8 (C4/C5 of Cht), 112.8 (ipsocarbon of Cht). ${ }^{55} \mathrm{Mn}-\mathrm{NMR}\left(74.4 \mathrm{MHz}, \mathrm{CD}_{3} \mathrm{CN}, \mathrm{ppm}\right): \delta=378.2$. IR $\left(\mathrm{ATR}, \mathrm{cm}^{-1}\right): 3117\left(\nu_{\mathrm{C}-\mathrm{H}}\right), 1459,1427,1384\left(\nu_{\mathrm{C}=\mathrm{C}}\right), 1030,1015$ $\left(\delta_{\mathrm{C}-\mathrm{H}}\right), 812\left(\nu_{\mathrm{P}-\mathrm{F}}\right), 554\left(\delta_{\mathrm{P}-\mathrm{F}}\right), 448\left(\nu_{\text {metal-ring }}\right)$. MS (ESI pos, $\left.\mathrm{m} / z\right)$ : $225.0467\left(\left[\mathrm{M}-\mathrm{PF}_{6}\right]^{+}\right)$, calcd for $\mathrm{C}_{13} \mathrm{H}_{14} \mathrm{Mn}: 225.0471$. UV/vis $\left(\mathrm{CH}_{3} \mathrm{CN}, \mathrm{nm}\right): \lambda_{\max 1}=278, \lambda_{\max 2}=547$. Single crystals of 10 were obtained from acetonitrile and diethyl ether at room temperature. Single-crystal analysis (Figure 2, Supporting Information).

$\eta^{7}$-Cycloheptatrienyl- $\eta^{5}$-methylcyclopentadienylmanganese (8-Methyltromancenium) Hexafluoridophosphate (11). Analogous to the synthesis of 9 described above, 11 was prepared starting from $0.385 \mathrm{~mL}$ of methylcymantrene $(2.45 \mathrm{mmol}, 1.00$ equiv), $404 \mu \mathrm{L}$ of 1,3,5-cycloheptatriene ( $3.86 \mathrm{mmol}, 1.50$ equiv), and $50 \mathrm{~mL}$ of dry heptane. Irradiation with blue light $(450 \mathrm{~nm})$ and 370 $\mathrm{W}$ for $45 \mathrm{~min}$ and subsequent reaction with tritylium hexafluoridophosphate (1.048 g, $2.70 \mathrm{mmol}, 1.10$ equiv) afforded 8methyltromancenium hexafluoridophosphate (11) as red crystals in $97.4 \%$ yield $(0.882 \mathrm{~g}, 2.38 \mathrm{mmol})$ in a calculated quantum yield of 3.2\%. Mp: $256{ }^{\circ} \mathrm{C}$ dec. ${ }^{1} \mathrm{H}$ NMR (300.1 MHz, $\left.\mathrm{CD}_{3} \mathrm{CN}, \mathrm{ppm}\right): \delta=$ $1.91\left(\mathrm{~s}, 3 \mathrm{H}, \mathrm{CH}_{3}\right), 4.67$ (s, 4H, C9-C12 of $\left.\mathrm{Cp}\right), 6.79(\mathrm{~s}, 7 \mathrm{H}, \mathrm{C} 1-7$ of $\mathrm{Cht}) .{ }^{13} \mathrm{C}$ NMR $\left(75.5 \mathrm{MHz}, \mathrm{CD}_{3} \mathrm{CN}, \mathrm{ppm}\right): \delta=13.0\left(\mathrm{CH}_{3}\right), 77.8$ (C9/C12 of Cp), 79.9 (C10/C11 of Cp), 97.8 (C1-7 of Cht), ipsocarbon of Cp not visible. ${ }^{55} \mathrm{Mn}-\mathrm{NMR}\left(74.4 \mathrm{MHz}, \mathrm{CD}_{3} \mathrm{CN}, \mathrm{ppm}\right): \delta=$ 256.9. IR (ATR, cm $\left.{ }^{-1}\right): 3123\left(\nu_{\mathrm{C}-\mathrm{H}}\right), 1449\left(\nu_{\mathrm{C}=\mathrm{C}}\right), 1016\left(\nu_{\mathrm{C}-\mathrm{H}}\right), 820$ $\left(\nu_{\mathrm{P}-\mathrm{F}}\right), 556\left(\nu_{\mathrm{P}-\mathrm{F}}\right), 447\left(\nu_{\text {metal-ring }}\right)$. HRMS (ESI pos, $\left.m / z\right): 225.0460$ $\left(\left[\mathrm{M}-\mathrm{PF}_{6}\right]^{+}\right)$, calcd for $\mathrm{C}_{13} \mathrm{H}_{14} \mathrm{Mn}: 225.0471$. UV/vis $\left(\mathrm{CH}_{3} \mathrm{CN}\right.$, $\mathrm{nm}): \lambda_{\max 1}=290, \lambda_{\max 2}=545$. Single crystals of 11 were obtained from acetonitrile and diethyl ether at room temperature. Single-crystal analysis (Figure 2, Supporting Information).

$\eta^{7}$-Cycloheptatrienyl- $\eta^{5}$-methoxycarbonylcyclopentadienylmanganese (8-Methoxycarbonyltromancenium) Hexafluoridophosphate (18). Analogous to the synthesis of 9 described above, 18 was prepared from methyl cymantrenecarboxylate $(\mathbf{1 2})^{12}$ $(0.080 \mathrm{~g}, 0.305 \mathrm{mmol}, 1.00$ equiv), 1,3,5-cycloheptatriene (42 $\mu \mathrm{L}$, $0.382 \mathrm{mmol}, 1.25$ equiv), and $13 \mathrm{~mL}$ of dry heptane. Irradiation with blue light $(450 \mathrm{~nm})$ and $370 \mathrm{~W}$ for $30 \mathrm{~min}$ and subsequent reaction with tritylium hexafluoridophosphate $(0.148 \mathrm{~g}, 0.382 \mathrm{mmol}, 1.25$ equiv) afforded 8-carbomethoxy-tromancenium hexafluoridophosphate $(\mathbf{1 8})$ as a lavender-colored powder in $19.0 \%$ yield $(0.024 \mathrm{~g}$, $0.0579 \mathrm{mmol})$, representing a quantum yield of $1.5 \% . \mathrm{Mp}: 208{ }^{\circ} \mathrm{C}$ dec. ${ }^{1} \mathrm{H}$ NMR (300.1 MHz, $\left.\mathrm{CD}_{3} \mathrm{CN}, \mathrm{ppm}\right): \delta=3.92\left(\mathrm{~s}, 3 \mathrm{H}, \mathrm{CH}_{3}\right)$, 4.87 (s, 2H, C10/C11 of Cp), $5.20(\mathrm{~s}, 2 \mathrm{H}, \mathrm{C} 9 / \mathrm{C} 12$ of $\mathrm{Cp}), 6.89(\mathrm{~s}$, $7 \mathrm{H}, \mathrm{C} 1-7$ of $\mathrm{Cht}) .{ }^{13} \mathrm{C} \mathrm{NMR}\left(75.5 \mathrm{MHz}, \mathrm{CD}_{3} \mathrm{CN}, \mathrm{ppm}\right): \delta=53.7$ $\left(\mathrm{CH}_{3}\right), 78.6(\mathrm{C} 10 / \mathrm{C} 11$ of $\mathrm{Cp}), 80.0$ (C9/C12 of $\left.\mathrm{Cp}\right), 81.5$ (ipsocarbon of $\mathrm{Cp}$ ), 98.8 (C1-7 of Cht), 167.9 (C13 of carbonyl). ${ }^{55} \mathrm{Mn}-$ NMR (74.4 MHz, $\left.\mathrm{CD}_{3} \mathrm{CN}, \mathrm{ppm}\right): \delta=538.2$. IR $\left(\mathrm{ATR}, \mathrm{cm}^{-1}\right): 3652$ (c=O overtone), 3122, $3081\left(\nu_{\mathrm{C}-\mathrm{H}}\right), 1714\left(\nu_{\mathrm{C}=\mathrm{O}}\right), 1476,1448,1437$, $1409,1381\left(\nu_{\mathrm{C}=\mathrm{C}}\right), 1292\left(\nu_{\mathrm{CO}-\mathrm{O}}\right), 1153\left({ }_{\nu \mathrm{O}-\mathrm{C}-\mathrm{C}}\right), 1034,965\left(\nu_{\text {ip C-H }}\right)$, $812\left(\nu_{\mathrm{P}-\mathrm{F}}\right), 554\left(\nu_{\mathrm{P}-\mathrm{F}}\right), 463\left(\nu_{\text {metal-ring }}\right)$. HRMS (ESI pos, $\left.[\mathrm{m} / z]\right)$ : $269.0348\left(\left[\mathrm{M}-\mathrm{PF}_{6}\right]^{+}\right.$, calcd for $\mathrm{C}_{14} \mathrm{H}_{14} \mathrm{MnO}_{2}:$ 269.0369. UV/vis $\left(\mathrm{CH}_{3} \mathrm{CN},[\mathrm{nm}]\right): \lambda_{\operatorname{max1}}=277, \lambda_{\max 2}=569$. Single crystals of 18 were obtained from acetonitrile and diethyl ether at room temperature. Single-crystal analysis (Figure 2, Supporting Information).

$\eta^{7}$-Cycloheptatrienyl- $\eta^{5}$-bromocyclopentadienylmanganese (8-Bromotromancenium) Hexafluoridophosphate (19). 
Analogous to the synthesis of 9 described above, 19 was prepared from bromocymantrene $(\mathbf{1 3})^{13}$ (0.0325 g, $0.115 \mathrm{mmol}, 1.00$ equiv), 1,3,5-cycloheptatriene ( $19 \mu \mathrm{L}, 0.172 \mathrm{mmol}, 1.50$ equiv), and $20 \mathrm{~mL}$ of dry heptane. Irradiation with blue light $(450 \mathrm{~nm})$ and $370 \mathrm{~W}$ for 2.30 min (Note: Longer irradiation times lead to undefined mixtures and significant yield loss) and subsequent reaction with tritylium hexafluoridophosphate $(0.067 \mathrm{~g}, 0.172 \mathrm{mmol}, 1.50$ equiv) afforded 8-bromotromancenium hexafluoridophosphate (19) as red crystals in $24.0 \%$ yield $(0.012 \mathrm{~g}, 0.028 \mathrm{mmol})$, representing a quantum yield of 2.7\%. Mp: $222{ }^{\circ} \mathrm{C}$ dec. ${ }^{1} \mathrm{H}$ NMR (300.1 MHz, $\left.\mathrm{CD}_{3} \mathrm{CN}, \mathrm{ppm}\right): \delta=$ 4.78 (pseudo-t, $2 \mathrm{H}, \mathrm{J}=2.1 \mathrm{~Hz}, \mathrm{C} 10 / \mathrm{C} 11$ of $\mathrm{Cp}$ ), 5.06 (pseudo-t, $2 \mathrm{H}$, $\mathrm{J}=2.1 \mathrm{~Hz}, \mathrm{C} 9 / \mathrm{C} 12$ of $\mathrm{Cp}$ ), 6.90 (s, 7H, C1-7 of Cht). ${ }^{13} \mathrm{C}$ NMR (75.5 MHz, $\left.\mathrm{CD}_{3} \mathrm{CN}, \mathrm{ppm}\right): \delta=77.3$ (C10/C11 of $\mathrm{Cp}$ ), 81.2 (C9/ $\mathrm{C} 12$ of $\mathrm{Cp}$ ), 86.4 (ipso-carbon of $\mathrm{Cp}$ ), 99.4 (C1-7 of Cht). ${ }^{55} \mathrm{Mn}$ NMR (74.4 MHz, $\left.\mathrm{CD}_{3} \mathrm{CN}, \mathrm{ppm}\right): \delta=368.4$. IR $\left(\mathrm{ATR}, \mathrm{cm}^{-1}\right): 3117$ $\left(\nu_{\mathrm{C}-\mathrm{H}}\right), 1447,1425,1399,1364\left(\nu_{\mathrm{C}=\mathrm{C}}\right), 1166,1025\left(\nu_{\mathrm{C}-\mathrm{H}}\right), 808$ $\left(\nu_{\mathrm{P}-\mathrm{F}}\right), 554\left(\nu_{\mathrm{P}-\mathrm{F}}\right), 448\left(\nu_{\text {metal-ring }}\right)$. HRMS (ESI pos, $\left.m / z\right): 288.9421$, $290.9398\left(\left[\mathrm{M}-\mathrm{PF}_{6}\right]^{+}\right)$, calcd for $\mathrm{C}_{12} \mathrm{H}_{11} \mathrm{BrMn}: 288.9419,290.9399$. $\mathrm{UV} /$ vis $\left(\mathrm{CH}_{3} \mathrm{CN}, \mathrm{nm}\right): \lambda_{\max 1}=280, \lambda_{\max 2}=550$. Single crystals of 19 were obtained from acetonitrile and diethyl ether at room temperature. Single-crystal analysis (Figure 2, Supporting Information).

$\eta^{7}$-Cycloheptatrienyl- $\eta^{5}$-aminocyclopentadienylmanganese (8-Aminotromancenium) Hexafluoridophosphate (20). Analogous to the synthesis of $\mathbf{9}$ described above, $\mathbf{2 0}$ was prepared from $0.124 \mathrm{~g}$ of aminocymantrene $(\mathbf{1 4})^{15}(0.565 \mathrm{mmol}, 1.00$ equiv $), 75 \mu \mathrm{L}$ of 1,3,5-cycloheptatriene ( $0.680 \mathrm{mmol}, 1.20$ equiv), and $10 \mathrm{~mL}$ of toluene (abs). Irradiation with blue light $(450 \mathrm{~nm})$ and $370 \mathrm{~W}$ for $3.40 \mathrm{~min}$ (Note: A chemoselective synthesis of 20 requires a meticulous control of the irradiation time, since excessive photochemical excitation leads to cleavage of the $\mathrm{C}-\mathrm{N}$ bond, resulting in the formation of unsubstituted tromancenium salt) and subsequent reaction with tritylium hexafluoridophosphate $(0.262 \mathrm{~g}, 0.675 \mathrm{mmol}$, 1.20 equiv) afforded air-stable 8-aminotromancenium hexafluoridophosphate $(\mathbf{2 0})$ as red crystals in $9.5 \%$ yield $(0.020 \mathrm{~g}, 0.054 \mathrm{mmol})$ with a quantum yield of $8.4 \%$. Mp: $245{ }^{\circ} \mathrm{C} \mathrm{dec} .{ }^{1} \mathrm{H}$ NMR (300.1 $\mathrm{MHz}, \mathrm{CD}_{3} \mathrm{CN}, \mathrm{ppm}$ ): $\delta=4.08$ (s, $2 \mathrm{H}, \mathrm{NH}_{2}$ ), 4.32 (pseudo-t, $2 \mathrm{H}, \mathrm{J}=$ $2.1 \mathrm{~Hz}, \mathrm{C} 9 / \mathrm{C} 12$ of $\mathrm{Cp}$ ), 4.43 (pseudo-t, $2 \mathrm{H}, \mathrm{J}=1.8 \mathrm{~Hz}, \mathrm{C} 10 / \mathrm{C} 11$ of $\mathrm{Cp}), 6.63(\mathrm{~s}, 7 \mathrm{H}, \mathrm{C} 1-7$ of $\mathrm{Cht}) .{ }^{13} \mathrm{C} \mathrm{NMR}\left(75.5 \mathrm{MHz}, \mathrm{CD}_{3} \mathrm{CN}\right.$, ppm): $\delta=65.3$ (C9/C12 of Cp), 73.3 (C10/C11 of Cp), 97.5 (C1-7 of Cht), 123.9 (ipso-carbon of Cp). ${ }^{55} \mathrm{Mn}-\mathrm{NMR}\left(74.4 \mathrm{MHz}, \mathrm{CD}_{3} \mathrm{CN}\right.$, ppm): $\delta=238.0$. IR $\left(\right.$ ATR, cm $\left.{ }^{-1}\right): 3502,3406\left(\nu_{\mathrm{N}-\mathrm{H}}\right), 3076\left(\nu_{\mathrm{C}-\mathrm{H}}\right)$, $1710,1628\left(\nu_{\mathrm{C}=\mathrm{C}}\right), 1074,1054,1033\left(\delta_{\mathrm{C}-\mathrm{H}}\right), 826\left(\nu_{\mathrm{P}-\mathrm{F}}\right), 555\left(\delta_{\mathrm{P}-\mathrm{F}}\right)$, 451, $437\left(\nu_{\text {metal-ring }}\right)$. MS (ESI pos, $\left.[\mathrm{m} / z]\right): 226.0419\left(\left[\mathrm{M}-\mathrm{PF}_{6}\right]^{+}\right)$, calcd for $\mathrm{C}_{14} \mathrm{H}_{14} \mathrm{MnO}_{2}: 226.0423$. UV/vis $\left(\mathrm{CH}_{3} \mathrm{CN}, \mathrm{nm}\right): \lambda_{\max 1}=$ $288, \lambda_{\max 2}=312, \lambda_{\max 3}=500$ (plateau). Single crystals of 20 were obtained from acetonitrile and diethyl ether at room temperature. Single-crystal analysis (Figure 2, Supporting Information).

\section{ASSOCIATED CONTENT}

\section{SI Supporting Information}

The Supporting Information is available free of charge at https://pubs.acs.org/doi/10.1021/acs.organomet.1c00376.

Spectra $\left({ }^{1} \mathrm{H} /{ }^{13} \mathrm{C} /{ }^{55} \mathrm{Mn}\right.$ NMR, IR, HRMS, UV-vis), photoelectron spectra (XPS), cyclic voltammograms, DFT results (PDF)

\section{Accession Codes}

CCDC 2079152-2079157 contain the supplementary crystallographic data for this paper. These data can be obtained free of charge via www.ccdc.cam.ac.uk/data_request/cif, or by emailing data_request@ccdc.cam.ac.uk, or by contacting The Cambridge Crystallographic Data Centre, 12 Union Road, Cambridge CB2 1EZ, UK; fax: +44 1223336033.

\section{AUTHOR INFORMATION}

\section{Corresponding Authors}

Benno Bildstein - Institute of General, Inorganic and Theoretical Chemistry, Center for Chemistry and Biomedicine, University of Innsbruck, 6020 Innsbruck, Austria; (o orcid.org/0000-0003-1969-1334;

Email: benno.bildstein@uibk.ac.at

Maren Podewitz - Institute of General, Inorganic and Theoretical Chemistry, Center for Chemistry and Biomedicine, University of Innsbruck, 6020 Innsbruck, Austria; (1) orcid.org/0000-0001-7256-1219; Email: maren.podewitz@uibk.ac.at

Rainer F. Winter - Department of Chemistry, University of Konstanz, 78457 Konstanz, Germany; 이잉.org/00000001-8381-0647; Email: rainer.winter@uni-konstanz.de

\section{Authors}

Reinhard Basse - Institute of General, Inorganic and Theoretical Chemistry, Center for Chemistry and Biomedicine, University of Innsbruck, 6020 Innsbruck, Austria

Stefan Vanicek - Institute of General, Inorganic and Theoretical Chemistry, Center for Chemistry and Biomedicine, University of Innsbruck, 6020 Innsbruck, Austria

Thomas Höfer - Institute of General, Inorganic and Theoretical Chemistry, Center for Chemistry and Biomedicine, University of Innsbruck, 6020 Innsbruck, Austria

Holger Kopacka - Institute of General, Inorganic and Theoretical Chemistry, Center for Chemistry and Biomedicine, University of Innsbruck, 6020 Innsbruck, Austria

Klaus Wurst - Institute of General, Inorganic and Theoretical Chemistry, Center for Chemistry and Biomedicine, University of Innsbruck, 6020 Innsbruck, Austria

Thomas Müller - Institute of Organic Chemistry, Center for Chemistry and Biomedicine, University of Innsbruck, 6020 Innsbruck, Austria; orcid.org/0000-0002-3400-3248

Heidi A. Schwartz - Institute of General, Inorganic and Theoretical Chemistry, Center for Chemistry and Biomedicine, University of Innsbruck, 6020 Innsbruck, Austria; orcid.org/0000-0001-9894-1527

Selina Olthof - Department of Chemistry, University of Cologne, 50939 Köln, Germany; @orcid.org/0000-00028871-1549

Larissa A. Casper - Department of Chemistry, University of Konstanz, 78457 Konstanz, Germany; 이잉.org/00000001-8944-2777

Moritz Nau - Department of Chemistry, University of Konstanz, 78457 Konstanz, Germany

Complete contact information is available at: https://pubs.acs.org/10.1021/acs.organomet.1c00376

\section{Author Contributions}

${ }^{\dagger}$ R.B. and S.V. contributed equally.

\section{Notes}

The authors declare no competing financial interest.

\section{ACKNOWLEDGMENTS}

We gratefully acknowledge funding by the Austrian Science Fund (FWF) (Grant Nos. P 33858-N, P 335280, J-4158, and 
M-2005). The computational results presented here have been achieved using the LEO HPC infrastructure at the University of Innsbruck.

\section{REFERENCES}

(1) Green, M. L. H.; Ng, D. K. P. Cycloheptatriene and -enyl Complexes of the Early Transition Metals. Chem. Rev. 1995, 95, 439473.

(2) (a) Lu, F.; Elschenbroich, C.; Harms, K.; Burghaus, O.; Pietzonka, C. Paramagnetic ([5]Trovacenyl)phenyl-phosphane: Intramolecular Electronic Communication and Construction of Heterobimetallic Palladium and Chromium Complexes. Eur. J. Inorg. Chem. 2015, 2015, 2883-2888. See also references cited therein. (b) Elschenbroich, C.; Paganelli, F.; Nowotny, M.; Neumüller, B.; Burghaus, $\mathrm{O}$. The [1]- and [2] Silatrovacenophanes $\left(\eta^{7}-\mathrm{C}_{7} \mathrm{H}_{6}\right) \mathrm{V}\left(\eta^{5}\right.$ $\left.\mathrm{C}_{5} \mathrm{H}_{4} \mathrm{SiR}_{2}\right)$ and $\left(\eta^{7}-\mathrm{C}_{7} \mathrm{H}_{6}\right) \mathrm{V}\left(\eta^{5}-\mathrm{C}_{5} \mathrm{H}_{4} \mathrm{SiR}_{2} \mathrm{SiR}_{2}(\mathrm{R}=\mathrm{Me}, \mathrm{Ph})\right.$ : Synthesis, Structure, and Ring Opening. Z. Anorg. Allg. Chem. 2004, 630, 1599-1606. See also references cited therein.

(3) (a) Tamm, M. Synthesis and reactivity of functionalized cycloheptatrienyl-cyclopentadienyl sandwich complexes. Chem. Commun. 2008, 3089-3100. (b) Glöckner, A.; Tamm, M. The organometallic chemistry of cycloheptatrienyl zirconium complexes. Chem. Soc. Rev. 2013, 42, 128-142.

(4) Braunschweig, H.; Friedrich, M.; Radacki, K.; Wolf, J. Synthesis and Reactivity of Palladium- and Platinum-Bridged Heterobimetallic [3] Trochrocenophanes. Organometallics 2012, 31, 3027-3034.

(5) Pittracher, M.; Frisch, U.; Kopacka, H.; Wurst, K.; Müller, T.; Oehninger, L.; Ott, I.; Wuttke, E.; Scheerer, S.; Winter, R. F. Bildstein, B. $\pi$-Complexes of Tropolone and Ist N-Derivatives: $[\mathrm{O}, \mathrm{O}] /[\mathrm{N}, \mathrm{O}] /$ $[\mathrm{N}, \mathrm{N}]$-Cycloheptatrienyl Pentamethylcyclopentadienyl Ruthenium Sandwich Complexes. Organometallics 2014, 33, 1630-1643.

(6) Fischer, E. O.; Breitschaft, S. Über Fünfring-SechsringAromaten-Metall- $\pi$-Komplexe des Chroms und Mangans und ihr anomales Verhalten bei Acylierungsversuchen nach Friedel-Crafts. Chem. Ber. 1966, 99, 2213-2226.

(7) (a) Pauson, P. L.; Segal, J. A. Complete photochemical carbonyl substitution in cyclopentadienyl-tricarbonylmanganese. J. Organomet. Chem. 1973, 63, C13-C14. (b) Pauson, P. L.; Segal, J. A. "( $\eta$ Cycloheptatriene)- and ( $\eta$-Cycloheptatrienylium)-( $\eta$ cyclopentadienyl)manganese. Formation of Cyclic Triene Complexes by Photochemical Displacement of Three Carbonyl Groups from Tricarbonyl-( $\eta$-cyclopentadienyl)manganese. J. Chem. Soc., Dalton Trans. 1975, 2387-2392. (c) Handbuch der Präparativen Anorganischen Chemie; Brauer, G., Ed.; Ferdinand Enke Verlag: Stuttgart, 1981, Vol. 3, p 1887. ISBN: 3-432-87823-0..

(8) Selected recent references of our work in cobaltocenium chemistry: (a) Vanicek, S.; Kopacka, H.; Wurst, K.; Müller, T.; Schottenberger, H.; Bildstein, B. Chemoselective, Practical Synthesis of Cobaltocenium Carboxylic Acid Hexafluorophosphate. Organometallics 2014, 33, 1152-1156. (b) Vanicek, S.; Kopacka, H.; Wurst, K.; Müller, T.; Hassenrück, C.; Winter, R. F.; Bildstein, B. Monofunctionalized Cobaltocenium Compounds by Dediazoniation Reactions of Cobaltoceniumdiazonium Bis(hexafluorophosphate). Organometallics 2016, 35, 2101-2109. (c) Vanicek, S.; Kopacka, H.; Wurst, K.; Vergeiner, S.; Kankowski, S.; Schur, J.; Bildstein, B.; Ott, I. Cobaltoceniumethynyl gold(I) as an unusual heterodinuclear bioorganometallic fragment to study the biological properties of alkynyl gold complexes. Dalton Trans. 2016, 45, 1345-1348. (d) Vanicek, S.; Podewitz, M.; Hassenrück, C.; Pittracher, M.; Kopacka, H.; Wurst, K.; Müller, T.; Liedl, K. R.; Winter, R. F.; Bildstein, B. Cobaltocenylidene: A Mesoionic Metalloceno Carbene, Stabilized in a Gold(III) Complex. Chem. - Eur. J. 2018, 24, 31653169. (e) Vanicek, S.; Podewitz, M.; Stubbe, J.; Schulze, D.; Kopacka, H.; Wurst, K.; Müller, T.; Lippmann, P.; Haslinger, S.; Schottenberger, H.; Liedl, K. R.; Ott, I.; Sarkar, B.; Bildstein, B. Highly Electrophilic, Catalytically Active and Redox-Responsive Cobaltoceniumyl and Ferrocenyl Triazolylidene Coinage Metal Complexes. Chem. - Eur. J. 2018, 24, 3742-3753. (f) Vanicek, S.;
Jochriem, M.; Hassenrück, C.; Roy, S.; Kopack, H.; Wurst, K.; Müller, T.; Winter, R. F.; Reisner, E.; Bildstein, B. Redox-Rich Metallocene Tetrazene Complexes: Synthesis, Structure, Electrochemistry, and Catalysis. Organometallics 2019, 38, 1361-1371. (g) Jochriem, M.; Bosch, D.; Kopacka, H.; Bildstein, B. Direct Amination of Cobaltocenium Hexafluoridophosphate via Vicarious Nucleophilic Substitution. Organometallics 2019, 38, 2278-2279. (h) Vanicek, S.; Beerhues, J.; Bens, T.; Levchenko, V.; Wurst, K.; Bildstein, B.; Tilset, M.; Sarkar, B. Oxidative Access via Aqua Regia to an Electrophilic, Mesoionic Dicobaltoceniumyltriazolylidene Gold(III) Catalyst. Organometallics 2019, 38, 4383-4386.

(9) Reviews: (a) Mukherjee, A.; Milstein, D. Homogeneous Catalysis by Cobalt and Manganese Pincer Complexes. ACS Catal. 2018, 8, 11435-11469. (b) Garbe, M.; Junge, K.; Beller, M. Homogeneous Catalysis by Manganese-Based Pincer Complexes. Eur. J. Org. Chem. 2017, 2017, 4344-4362.

(10) Bartenbach Holding GmbH, Lichtreaktor sowie Verfahren zur synthetischen Stofferzeugung mittels Lichtbestrahlung. Patent pending, 2020121117052200DE, 2020.

(11) Biehl, E. R.; Reeves, P. C. A Convenient, High-Yield Synthesis of the Carboxylic Acid Derivatives of Ferrocene and Cyclopentadienylmanganese Tricarbonyl. Synthesis 1973, 360-361.

(12) (a) Hart, W. P.; Shihua, D.; Rausch, M. D. The Formation and Reactions of $\left(\eta^{5}\right.$-Carboxylcyclopentadienyl)dicarbonylcobalt. J. Organomet. Chem. 1985, 282, 111-121. (b) Jones, S. S.; Rausch, M. D.; Bitterwolf, T. E. Formation and synthetic utility of formyl-, acetyl-, carbomethoxy- and carboethoxy-cyclopentadienylthallium. J. Organomet. Chem. 1990, 396, 279-287.

(13) (a) Weil, T.; Cais, M. A Simplified Procedure for the Preparation of Diazocyclopentadiene ans Some Related Compounds. J. Org. Chem. 1963, 28, 2472. (b) Conway, B. G.; Rausch, M. D. Formation and Reactivity of Halogen Derivatives of $\left(\eta^{5}\right.$ Cyclopentadienyl)thallium. Organometallics 1985, 4, 688-693.

(14) Lynch, T. J.; Dominguez, R.; Helvenston, M. C. Synthesis of the Trimetallic Manganese and Rhenium Complexes $\mathrm{N}\left[\mathrm{CH}_{2}\left(\eta^{5}\right.\right.$ $\left.\left.\mathrm{C}_{5} \mathrm{H}_{4}\right) \mathrm{M}(\mathrm{CO})_{3}\right]_{3}$. Derivatives of the Nonadentate "TCp" Ligand, Tris(cyclopentadienylmethyl)amine Trianion. Organometallics 1988, 7, 2566-2567.

(15) (a) Holovics, T. C.; Deplazes, S. F.; Toriyama, M.; Powell, D. R.; Lushington, G. H.; Barybin, M. V. Organometallic Isocyanocyclopentadienides: A Combined Synthetic, Spectroscopic, Structural, Electrochemical, and Theoretical Investigation. Organometallics 2004, 23, 2927-2938. (b) Day, P. D.; Dann, T.; Hughes, D. L.; Oganesyan, V. S.; Steverding, D.; Wildgoose, G. G. Cymantrene-Triazole "Click" Products: Structural Characterization and Electrochemical Properties. Organometallics 2014, 33, 4687-4696.

(16) Pauson, P. L. Nucleophilic addition to transition metal complexes. J. Organomet. Chem. 1980, 200, 207-221.

(17) Ginzburg, A. G. The chemistry of cymantrene. Russ. Chem. Rev. 2009, 78, 195-210.

(18) Wrackmeyer, B.; Hofmann, T.; Herberhold, M. Characterization of manganese sandwich complexes by ${ }^{55} \mathrm{Mn}$ NMR spectroscopy. J. Organomet. Chem. 1995, 486, 255-258.

(19) Hoffmann, F.; Wagler, J.; Roewer, G. Transition-Metal Compounds Containing Alkynylsilyl Groups - Cyclopentadienyl Complexes. Eur. J. Inorg. Chem. 2012, 2012, 6018-6026.

(20) Hansch, C.; Leo, A.; Taft, R. W. A Survey of Hammett Substituent Constants and Resonance and Field Parameters. Chem. Rev. 1991, 91, 165-195.

(21) (a) Zeinstra, J. D.; De Boer, J. L. Structure of cyclopentadienylcycloheptatrienyl-titanium. J. Organomet. Chem. 1973, 54, 207-211. (b) Lyssenko, K. A.; Antipin, M. Yu.; Ketkov, S. Yu. Electron density distribution in vanadocene $\left(\eta^{5}-\mathrm{C}_{5} \mathrm{H}_{5}\right)_{2} \mathrm{~V}$ and mixed metallocenes $\left(\eta^{5}-\mathrm{C}_{5} \mathrm{H}_{5}\right) \mathrm{M}\left(\eta^{5}-\mathrm{C}_{7} \mathrm{H}_{7}\right)(\mathrm{M}=\mathrm{Ti}$, V, or $\mathrm{Cr})$ and $\left(\eta^{5}\right.$ $\left.\mathrm{C}_{5} \mathrm{H}_{5}\right) \mathrm{Ti}\left(\eta^{8}-\mathrm{C}_{8} \mathrm{H}_{8}\right)$. Effect of the nature of the cyclic ligand on the character of the $\mathrm{M}-(\pi$-ligand) bond. Russ. Chem. Bull. 2001, 50, 130-141. (c) Mohapatra, S. K.; Büschel, S.; Daniliuc, C.; Jones, P. G.; Tamm, M. Selective Lithiation and Phosphane-Functionalization of $\left[\left(\eta^{7}-\mathrm{C}_{7} \mathrm{H}_{7}\right) \mathrm{Ti}\left(\eta^{5}-\mathrm{C}_{5} \mathrm{H}_{5}\right)\right]$ (Troticene) and Its Use for the Preparation 
of Early-Late-Heterobimetallic Complexes. J. Am. Chem. Soc. 2009, 131, 17014-17023. (d) Niinisto, J.; Hatanpaa, T.; Kariniemi, M.; Mantymaki, M.; Costelle, L.; Mizohata, K.; Kukli, K.; Ritala, M.; Leskela, M. Cycloheptatrienyl Cyclopentadienyl Heteroleptic Precursors for Atomic Layer Deposition of Group 4 Oxide Thin Films. Chem. Mater. 2012, 24, 2002-2008. (e) Tagne Kuate, A. C.; Sameni, S.; Freytag, M.; Jones, P. G.; Tamm, M. Phosphane-Functionalized Cycloheptatrienyl-Cyclopentadienyl Titanium Sandwich Complexes: Phosphorus Ligands with an Integrated Reducing Agent for Palladium(0) Catalyst Generation. Angew. Chem., Int. Ed. 2013, 52, 8638-8642. (f) Green, J. C.; Green, M. L. H.; Laltsoyannis, N.; Mountford, P.; Scott, P.; Simpson, S. J. Synthesis and Electronic and Molecular Structures of $\eta$-Cycloheptatrienyl $\eta$-Cyclopentadienyl Derivatives of Vanadium, Niobium, and Tantalum: Photoelectron Spectroscopic, Electrochemical, and X-ray Crystallographic Study. Organometallics 1992, 11, 3353-3361. (g) Elschenbroich, C.; Schiemann, O.; Burghaus, O.; Harms, K. Exchange Interaction Mediated by $\mathrm{O}-\mathrm{H}^{\prime \prime} \mathrm{O}$ Hydrogen Bonds: Synthesis, Structure, and EPR Study of the Paramagnetic Organometallic Carboxylic Acid $\left(\eta^{7}\right.$. $\left.\mathrm{C}_{7} \mathrm{H}_{7}\right) \mathrm{V}\left(\eta^{5}-\mathrm{C}_{5} \mathrm{H}_{4} \mathrm{COOH}\right.$. J. Am. Chem. Soc. 1997, 119, 7452-7457. (h) Elschenbroich, C.; Plackmeyer, J.; Nowotny, M.; Harms, K.; Pebler, J.; Burghaus, O. Di([5]trovacenyl)ethyne, $\mathrm{Di}([5]$ trovacenyl)butydiyne, and Di-1,4-([5]trovacenylethynyl)benzene: Electrocommunication and Magnetocommunication Mediated by - CC-, $\mathrm{CC}-\mathrm{CC}-$ and $-\mathrm{CC}-\mathrm{C}_{6} \mathrm{H}_{4}-\mathrm{CC}-$ Spacers. Inorg. Chem. 2005, 44, 955-963.

(22) Biesinger, M. C.; Payne, B. P.; Crosvenor, A. P.; Lau, L. W. M.; Gerson, A. R.; Smart, R. St. C. Resolving surface chemical states in XPS analysis of first row transition metals, oxides and hydroxides: $\mathrm{Cr}$, $\mathrm{Mn}, \mathrm{Fe}, \mathrm{Co}$ and Ni. Appl. Surf. Sci. 2011, 257, 2717-2730.

(23) (a) Gourier, D.; Samuel, E. EPR, ENDOR, and Optical Absorption Studies on the Electrochemically Produced Cycloheptatrienylcyclopentadienyltitanium $\left[\left(\eta^{5}-\mathrm{C}_{5} \mathrm{H}_{5}\right) \mathrm{Ti}\left(\eta^{7}-\mathrm{C}_{7} \mathrm{H}_{7}\right)\right]$ Anion radical. Inorg. Chem. 1988, 27, 3018-3024. (b) Anderson, J. E.; Maher, E. T.; Kool, L. B. Electrochemical and Spectroelectrochemical Properties of the Titanium Sandwich Complexes $(\mathrm{Cp}) \mathrm{Ti}(\mathrm{L})$ and $\left(\mathrm{Cp}^{*}\right) \mathrm{Ti}(\mathrm{L})$, Where $\mathrm{L}$ Is either Cyclooctatetraene $\left(\mathrm{C}_{8} \mathrm{H}_{8}\right)$ or the Tropylium Ion $\left(\mathrm{C}_{7} \mathrm{H}_{7}^{+}\right.$. Organometallics 1991, 10, $1248-1254$.

(24) (a) Koelle, U.; Holzinger, W.; Müller, J. Elektrochemie von Übergangsmetall- $\pi$-Komplexen, III* Olefin- und Aromatenkomplexe des Chroms. Z. Naturforsch., B: J. Chem. Sci. 1979, 84b, 759-761. (b) Elschenbroich, C.; Bilger, E.; Metz, B. Metal $-\pi$ Complexes of Benzene Derivatives. 37. ${ }^{1}$ Redox Behavior of the Sandwich Complexes $\mathrm{C}_{12} \mathrm{H}_{12} \mathrm{M}\left(\mathrm{C}_{12} \mathrm{H}_{12}=\mathrm{C}_{6} \mathrm{H}_{6}+\mathrm{C}_{6} \mathrm{H}_{6}, \mathrm{C}_{5} \mathrm{H}_{5}+\mathrm{C}_{7} \mathrm{H}_{7} ; \mathrm{M}=\mathrm{V}, \mathrm{Cr}\right) . \mathrm{A}$ Comparative Study. Organometallics 1991, 10, 2823-2827. (c) Elschenbroich, C.; Wolf, M.; Burghaus, O.; Harms, K.; Pebler, J. Trovacene Chemistry, $3^{[\neq]}$The Mono-, Di-, and tri([5]trovacenyl)boranes: A Study of Intermetallic Communication Across an $\mathrm{sp}^{2}$ Hybridized Boron Atom. Eur. J. Inorg. Chem. 1999, 1999, 2173-2185.

(25) Elshchenbroich, C.; Gerson, F.; Stohler, F. Spin Density Distribution in Unsymmetrical Sandwich Complexes. II. Electron Spin Resonance Studies of $\pi$-Cyclopentadienyl- $\pi$ cycloheptatrienechromium(I) and $\pi$-Cyclopentadienyl- $\pi$ cycloheptatrienylchromium(-I) Radical Anion. J. Am. Chem. Soc. 1973, 95, 6956.

(26) Prins, R.; Reinders, F. J. Electron spin resonance measurements of dibenzenechromium cation. Chem. Phys. Lett. 1969, 3, 45.

(27) (a) Richards, T. C.; Geiger, W. E. Competition between Homogeneous and Heterogeneous Electron-Transfer Pathways in an Electrochemical Square Scheme. J. Am. Chem. Soc. 1994, 116, 20282033. (b) Geiger, W. E. Structural Changes Accompanying Metal Complex Electrode Reactions. Prog. Inorg. Chem.; Lippard, S. J., Ed.; John Wiley and Sons: New York, 1985; Vol. 33, p 275. (c) Wooster, T. T.; Geiger, W. E. Quantitative Study of the Interconversion of $S$ and $\mathrm{U}$ Isomers of $\mathrm{Cp}\left(\eta^{5}\right.$-pentadienyl $) \mathrm{Cr}(\mathrm{CO})$ in 18- and 17-Electron Complexes: Cyclic Voltammetric Study of an Organometallic Square Scheme. Organometallics 1995, 14, 3455-3460.
(28) Emilia, M.; Silva, N.P.R.A.; Pombeiro, A. J.L.; da Silva, J. J.R.F.; Herrmann, R.; Deus, N.; Castilho, T. J.; Silva, M.F. C.G. Redox potential and substituent effects at ferrocene derivatives. Estimates of Hammett $\sigma_{\mathrm{p}}$ and Taft polar $\sigma^{*}$ substituent constants. J. Organomet. Chem. 1991, 421, 75-90.

(29) Wang, H. Y.; Xie, Y. M.; Silaghi-Dumitrescu, I.; King, R. B.; Schaefer, H. F. The mixed sandwich compounds $\mathrm{C}_{5} \mathrm{H}_{5} \mathrm{MC}_{7} \mathrm{H}_{7}$ of the first row transition metals: variable hapticity of the seven-membered ring. Mol. Phys. 2010, 108 (7-9), 883-894.

(30) Drabik, G.; Szklarzewicz, J.; Radon, M. Spin-state energetics of metallocenes: How do best wave function and density functional theory results compare with experimental data? Phys. Chem. Chem. Phys. 2021, 23, 151-172.

(31) Carret, S.; Depres, J.-P. Access to Guaianolides: Highly Efficient Stereocontrolled Total Synthesis of $( \pm)$-Geigerin. Angew. Chem., Int. Ed. 2007, 46, 6870-6873.

(32) Adamo, C.; Barone, V. Toward reliable density functional methods without adjustable parameters: The PBE0 model. J. Chem. Phys. 1999, 110, 6158-6170.

(33) (a) Becke, A. D. Density-Functional Exchange-Energy Approximation With Correct Asymptotic-Behavior. Phys. Rev. A: At., Mol., Opt. Phys. 1988, 38 (6), 3098-3100. (b) Perdew, J. P. DensityFunctional Approximation for the Correlation-Energy of The Inhomogeneous Electron-Gas. Phys. Rev. B: Condens. Matter Mater. Phys. 1986, 33, 8822-8824.

(34) Chai, J. D.; Head-Gordon, M. Long-range corrected hybrid density functionals with damped atom-atom dispersion corrections. Phys. Chem. Chem. Phys. 2008, 10 (44), 6615-6620.

(35) Weigend, F.; Ahlrichs, R. Balanced Basis Sets of Split Valence, Triple Zeta Valence and Quadruple Zeta Valence Quality For $\mathrm{H}$ to Rn: Design and Assessment of Accuracy. Phys. Chem. Chem. Phys. 2005, 7, 3297-3305.

(36) Eichkorn, K.; Treutler, O.; Ohm, H.; Häser, M.; Ahlrichs, R. Auxiliary Basis-Sets To Approximate Coulomb Potentials. Chem. Phys. Lett. 1995, 240, 283-289.

(37) (a) Grimme, S.; Antony, J.; Ehrlich, S.; Krieg, H. A consistent and accurate $a b$ initio parametrization of density functional dispersion correction (DFT-D) for the 94 elements H-Pu. J. Chem. Phys. 2010, 132, 154104. (b) Grimme, S.; Ehrlich, S.; Goerigk, L. Effect of the Damping Function in Dispersion Corrected Density Functional Theory. J. Comput. Chem. 2011, 32, 1456-1465.

(38) (a) Klamt, A.; Schüürmann, G. COSMO - A New Approach to Dielectric Screening In Solvents with Explicit Expressions for the Screening Energy and Its Gradient. J. Chem. Soc., Perkin Trans. 2 1993, 2, 799-805. (b) Schafer, A.; Klamt, A.; Sattel, D.; Lohrenz, J. C. W.; Eckert, F. COSMO Implementation in TURBOMOLE: Extension of an efficient quantum chemical code towards liquid systems. Phys. Chem. Chem. Phys. 2000, 2, 2187-2193.

(39) Zhao, Y.; Schultz, N. E.; Truhlar, D. G. Design of density functionals by combining the method of constraint satisfaction with parametrization for thermochemistry, thermochemical kinetics, and noncovalent interactions. J. Chem. Theory Comput. 2006, 2, 364-382.

(40) Frisch, M. J.; Trucks, G. W.; Schlegel, H. B.; Scuseria, G. E.; Robb, M. A.; Cheeseman, J. R.; Scalmani, G.; Barone, V.; Petersson, G. A.; Nakatsuji, H.; Li, X.; Caricato, M.; Marenich, A. V.; Bloino, J.; Janesko, B. G.; Gomperts, R.; Mennucci, B.; Hratchian, H. P.; Ortiz, J. V.; Izmaylov, A. F.; Sonnenberg, J. L.; Williams; Ding, F.; Lipparini, F.; Egidi, F.; Goings, J.; Peng, B.; Petrone, A.; Henderson, T.; Ranasinghe, D.; Zakrzewski, V. G.; Gao, J.; Rega, N.; Zheng, G.; Liang, W.; Hada, M.; Ehara, M.; Toyota, K.; Fukuda, R.; Hasegawa, J.; Ishida, M.; Nakajima, T.; Honda, Y.; Kitao, O.; Nakai, H.; Vreven, T.; Throssell, K.; Montgomery, J. A., Jr.; Peralta, J. E.; Ogliaro, F.; Bearpark, M. J.; Heyd, J. J.; Brothers, E. N.; Kudin, K. N.; Staroverov, V. N.; Keith, T. A.; Kobayashi, R.; Normand, J.; Raghavachari, K.; Rendell, A. P.; Burant, J. C.; Iyengar, S. S.; Tomasi, J.; Cossi, M.; Millam, J. M.; Klene, M.; Adamo, C.; Cammi, R.; Ochterski, J. W.; Martin, R. L.; Morokuma, K.; Farkas, O.; Foresman, J. B.; Fox, D. J. Gaussian 16 Rev. C.01; Wallingford, CT, 2016. 
(41) Kesharwani, M. K.; Brauer, B.; Martin, J. M. L. Frequency and Zero-Point Vibrational Energy Scale Factors for Double-Hybrid Density Functionals (and Other Selected Methods): Can Anharmonic Force Fields Be Avoided? J. Phys. Chem. A 2015, 119, 1701-1714.

(42) Ribeiro, R. F.; Marenich, A. V.; Cramer, C. J.; Truhlar, D. G. Use of Solution-Phase Vibrational Frequencies in Continuum Models for the Free Energy of Solvation. J. Phys. Chem. B 2011, 115 (49), $14556-14562$.

(43) Hirshfeld, F. L. Bonded-Atom Fragments for Describing Molecular Charge-Densities. Theor. Chim. Acta 1977, 44 (2), 129138.

(44) (a) Furche, F.; Ahlrichs, R.; Hattig, C.; Klopper, W.; Sierka, M.; Weigend, F. Turbomole. Wiley Interdiscip. Wiley Interdiscip. Rev.: Comput. Mol. Sci. 2014, 4, 91-100. (b) TURBOMOLE V7.3 2018, a development of University of Karlsruhe and Forschungszentrum Karlsruhe GmbH, 1989-2007, TURBOMOLE GmbH, since 2007; available from http://www.turbomole.com.

(45) Schrodinger, LLC PyMOL Molecular Graphics System, Version 2.1. 2020.

(46) Humphrey, W.; Dalke, A.; Schulten, K. VMD: Visual Molecular Dynamics. J. Mol. Graphics 1996, 14, 33-38. 